\title{
The In Situ Ion Irradiation Toolbox: Time-Resolved Structure and Property Measurements
}

\author{
E. LANG (i), ${ }^{1}$ C.A. DENNETT ${ }^{2},{ }^{2,3}$ N. MADDEN,${ }^{1}$ and K. HATTAR ${ }^{1,4}$ \\ 1.-Sandia National Laboratories, Albuquerque, NM 87123, USA. 2.-Materials Science and \\ Engineering Department, Idaho National Laboratory, Idaho Falls, ID 83415, USA. 3.-Nuclear \\ Science and Engineering Department, Massachusetts Institute of \\ Technology, Cambridge, MA 02139, USA. 4.-e-mail: khattar@sandia.gov
}

The dynamic interactions of ions with matter drive a host of complex evolution mechanisms, requiring monitoring on short spatial and temporal scales to gain a full picture of a material response. Understanding the evolution of materials under ion irradiation and displacement damage is vital for many fields, including semiconductor processing, nuclear reactors, and space systems. Despite materials in service having a dynamic response to radiation damage, typical characterization is performed post-irradiation, washing out all information from transient processes. Characterizing active processes in situ during irradiation allows the mechanisms at play during the dynamic ion-material interaction process to be deciphered. In this review, we examine the in situ characterization techniques utilized for examining material structure, composition, and property evolution under ion irradiation. Covering analyses of microstructure, surface composition, and material properties, this work offers a perspective on the recent advances in methods for in situ monitoring of materials under ion irradiation, including a future outlook examining the role of complementary and combined characterization techniques in understanding dynamic materials evolution.

\section{INTRODUCTION}

Ion irradiation of materials on various spatial and temporal scales is used to alter material microstructures, compositions, properties, and functions. Material structure and performance can be enhanced or degraded through the reorganization of surfaces, the implantation of chemical species, or the creation of defects depending on the ion species, energy, angle, etc., leading to sputtering, ${ }^{1,2}$ accumulation of defects, phase changes, ${ }^{3}$ morphological changes, surface structures, ${ }^{4,5}$ inducing nanostructures on polymers, ${ }^{6}$ semiconductors,${ }^{7}$ and metals. ${ }^{8}$ Ion beams can also be used for implantation, ${ }^{9}$ waveguide formation, ${ }^{10}$ functionalization of interfaces and surfaces, or emulation of exposure to extreme radiation environments, such as outer space or nuclear reactors. ${ }^{11-14}$

(Received September 6, 2021; accepted October 19, 2021; published online November 24, 2021)
Post-irradiation examination (PIE) is typically conducted to examine the impact of irradiation on materials. Evaluating post-irradiation microstructural evolution can be done with a variety of microscopies from optical to electron, through compositional analysis with surface and bulk spectroscopies, and through a wide range of property testing platforms. However, PIE is not ideal for understanding the dynamic evolution of materials exposed to ion beams as it only offers two examination conditions: pristine and post-irradiation. These snapshots in time cannot directly provide the transient microstructures and properties that dictate the final behavior. Tailoring the properties of advanced materials requires an understanding of the full temporal and spatial dynamics during exposure to precisely engineer targeted performance. In situ measurements during ion irradiation allow for the transient behavior of materials to be deciphered. With in situ characterization focusing on the microstructure, properties, and performance of materials, continuous time-resolved monitoring of 
these dynamics becomes possible. The ability to diagnose the damage to or modification of materials depends on the quality and nature of the characterization method used. Elucidating the transient states correlating structure-property relationships in materials in real time can be used to enhance our fundamental understanding of material evolution and thus better design engineered materials.

As a result, there is a need for facilities that characterize materials at combined spatial and temporal scales to probe their structure and performance in situ under complex radiation environments. Various characterization tools exist to probe materials ex situ on many length scales, offering morphological and compositional information, along with material properties, including $\mathrm{x}$-ray techniques, electron beam imaging, and laser-based spectroscopies. Integrating these techniques within ion irradiation facilities enhances our understanding of the dynamics of ion-material interactions to advance material design and function.

In this short review, we summarize methods used for in situ monitoring of materials under ion irradiation. Figure 1 highlights the structure and property analysis methods which have been deployed as in situ irradiation tools. In addition, potential new techniques that could be incorporated with in situ irradiation are discussed. This review starts with structure and composition, transitions to characterizing material properties, traversing across the probe wavelengths of in situ materials characterization tools deployed for materials under irradiation with ions. This review will focus on in situ materials characterization tools for ions with energies from $\sim 1 \mathrm{MeV}$ to $\sim 100 \mathrm{MeV}$ as significant diagnostics and studies have been performed on other energy ranges, including those found in focused ion beam (FIB) microscopes (lower energies) ${ }^{15}$ to high energy physics. ${ }^{16}$ With this coverage of current and upcoming in situ irradiation techniques, we hope to offer experiment designers a concise accounting of tools available to target whichever type of dynamic behavior is of interest to them.

\section{IN SITU STRUCTURE CHARACTERIZATION TOOLS}

\section{Ion Beam Characterization Techniques}

While the primary focus of this review will be on ion beams as tools to introduce damage and alter materials, they are also routinely utilized to characterize materials through Ion Beam Analysis (IBA) techniques. Facilities for in situ IBA including Rutherford Backscatter Spectrometry (RBS) and Elastic Recoil Detection Analysis (ERDA) of materials under ion irradiation have been designed to study irradiation dynamics. Use cases include the behavior of materials under nuclear reactor-relevant ion exposure conditions, ${ }^{17-19}$ defect fundamentals in semiconductors, ${ }^{20}$ perovskites, ${ }^{21}$ and metals ${ }^{22}$ chemical degradation of polymers ${ }^{23}$ and atomic mixing at metal-ceramic interfaces. ${ }^{24}$ Through these techniques, the dynamic depth-resolved composition and crystallinity can be deciphered in real-time, but the nuanced study of individual microstructural defects and the subsequent properties are not possible.

\section{Electron and Positron Beam Characterization Techniques}

The direct evolution of morphology and defects in real-time either at the nano- or micro-scales can be probed at high resolution via electron beam imaging. Analyzing the surface and sub-surface structure of materials in real time is important in

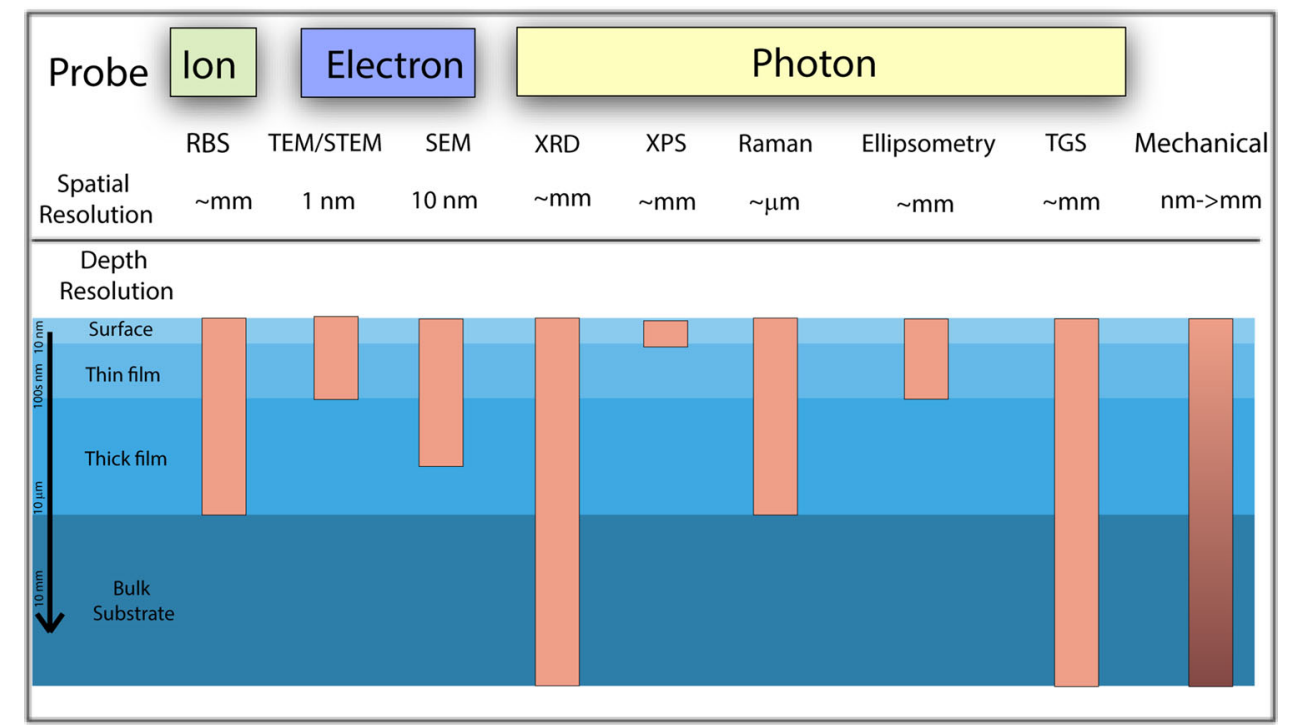

Fig. 1. Schematic of characterization tools and associated depth resolutions which have been deployed for structural and property interrogation of materials during ion irradiation. 
understanding dynamic evolution, as evolving microstructures dictate the performance and appropriate applications of materials

Few systems have been developed for in situ monitoring of materials under irradiation in a Scanning Electron Microscope (SEM). The microONE system, shown in Fig. 3a at Sandia National Laboratories represents one of the only integrated in situ SEM/ion irradiation facilities currently operating. ${ }^{25}$ With this analysis, irradiation-induced surface morphology changes of any material that can be imaged in an SEM can be probed in real-time, offering a dynamic understanding of surface evolution. Initial results have focused on the morphology of the nanoscintillator material $\mathrm{PbWO}_{4}$ powder under proton irradiation as shown in Fig. 2.

There are multiple benefits and drawbacks to imaging materials under simultaneous irradiation in the SEM. This analysis method offers high resolution imaging of the surface morphology of a bulk material and allows for spatial chemistry information with energy dispersive x-ray (EDS) analysis and spatial crystallographic information with electron backscatter diffraction (EBSD) analysis. However, there are synergistic electron and ion beam effects that must be considered. Energetic electron and ion beams can both introduce defects, heat samples, charge samples, or change material chemistry while imaging, all of which can complicate identification of ion-induced mechanisms. ${ }^{26,27}$ In the example presented in Fig. 2, the high magnification SEM imaging resulted in clear charging and ablation of the $\mathrm{PbWO}_{4}$ powder from the surface. As such, care must be taken to isolate the effects of ion damage in all in situ electron microscopy irradiation experiments. More generally, the observer effect needs to be extensively considered in any and all in situ techniques. Additionally, concerns regarding the integrity and performance of secondary and backscatter electron detectors in SEMs must be considered. Many detectors are susceptible to damage by ion beams or may be overloaded by ion-induced secondary electron emission, necessitating the use of creative experimental designs and imaging schemes. Nonetheless, in situ SEMs represent an emerging opportunity to study the evolving surface of materials under irradiation. Figure $3 \mathrm{a}-\mathrm{b}$ shows two in situ irradiation SEM systems.

After IBA, the combination of in situ transmission electron microscopy (TEM) with ion irradiation is probably the most common in situ tool and has been reviewed elsewhere. ${ }^{28,29}$ Figure 3c-e shows three examples of in situ irradiation TEM facilities around the world. The nanometer resolution of the TEM is ideal for observing the dynamics of dislocation loop nucleation and growth, bubble formation, bubble to cavity evolution, grain growth, phase transformations, phase segregation, and many other microstructural process in real-time through electron beam imaging and diffraction. However, the thin film nature of the TEM observation can complicate the interpretation of results due to the small volume of material and the higher surface-tovolume ratio. But, with proper experimental design, these limitations can be minimized. This section will highlight the general capabilities of the in situ ion irradiation within the TEM, with examples of materials under heavy, light, and multi-beam ion irradiation.

Ion irradiation within the TEM is primarily used to create either knock-on type damage or chemical doping within the TEM lamella. Any material that can be made into a TEM specimen can be studied during in situ ion bombardment including metals, ${ }^{30-40}$ nanoparticle systems, ${ }^{38,41,42}$ and ceramics. ${ }^{43-45}$ These facilities and the subsequent studies have demonstrated the potential benefit of nanostructure materials to engineer radiation tolerance. ${ }^{46,47}$ Figure 4 displays the power of in situ TEM studies which allow, for example, the continuous monitoring of crystal order and disorder at oxide interfaces, ${ }^{48}$ and visualization of irradiationinduced dislocation loop motion in $\mathrm{Cu}^{49}$ Both of these examples highlight the use of in situ TEM to understand dynamic defect mechanisms that drive bulk material responses.

In situ He and other noble gas ion implantation is used to investigate gas bubble and cavity formation and evolution in materials in real-time. In situ TEM has been used to examine He bubble formation and microstructural response in materials proposed for use in nuclear reactors, such as $\mathrm{W},{ }^{50,51}$ zircaloy, ${ }^{52}$ $\mathrm{Mo},{ }^{53} \mathrm{SiC}^{54,55}$ and $\mathrm{Si}^{37}$ as well as in model metal systems such as $\mathrm{Fe}^{56,57}$ and $\mathrm{Ni}, \mathrm{NiCr}$, and $\mathrm{FeCr},{ }^{56}$ and in minerals to simulate the effects of solar winds on space dust. ${ }^{58}$ Particular interest has been dedicated to deciphering the impacts of grain boundaries on $\mathrm{He}$ bubble dynamics, elucidating the He-bubble tolerance of nano-grained or nanostructured materials..$^{50,57,59}$

While single ion irradiation offers information on the mechanisms dictating fundamental material responses, materials in harsh environments such as nuclear reactors may be exposed to simultaneous, multiple particle bombardment, or complex nuclear reactions. Therefore, concurrent irradiations of materials with both a range of ion species and energies are needed to simulate these complex environments. Studies have examined the mobility of dislocations in $\mathrm{Fe}$ in the presence of $\mathrm{He},{ }^{60}$ bubble growth and linkage behavior in $\mathrm{SiC},{ }^{61}$ void formation in $\mathrm{Ni}^{62}$ and the dependence of single, dual, and triple ion beam (helium/deuterium/gold) irradiation on cavity formation and evolution. ${ }^{63}$ Overall, in situ TEM irradiation has proven one of the most consistent and reliable tools for the investigation of the transient, ion-induced effects on materials at the nanoscale. Additionally, advanced analytical microscopy tools have been deployed recently on multibeam irradiation facilities to probe the chemistry and structure of materials through Electron Energy 

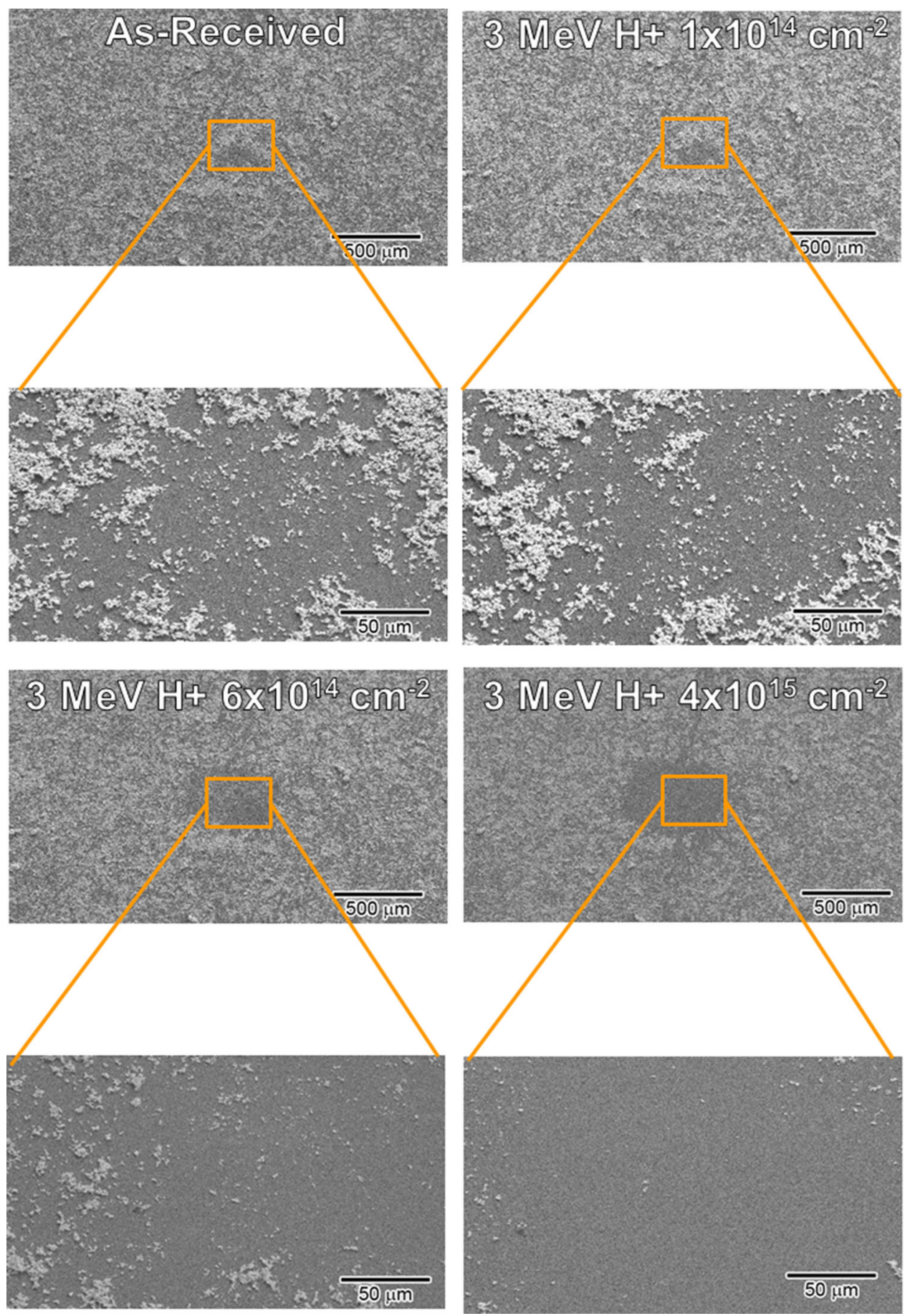

Fig. 2. In situ proton irradiation of $\mathrm{PbWO}_{4}$ within the SEM. The lack of topographical SEM contrast indicates material ablation following localized exposure to a $3 \mathrm{MeV} \mathrm{H}$ ion beam to the indicated fluences in the region of interest (orange box) demonstrating the ability for localized monitoring of surface damage of materials under irradiation.

Loss Spectroscopy (EELS), Energy Filtered-TEM (EF-TEM), Scanning Transmission Electron Microscopy (STEM), Energy Dispersive x-ray Spectroscopy (EDXS $)^{64}$ and Automated Crystal Orientation Mapping (ACOM) ${ }^{65}$

In addition to electrons, positrons are also used to investigate defect evolution within materials through positron annihilation spectroscopy (PAS or PALS). Capabilities for in situ positron doppler broadening for investigating defect evolution of bulk materials under irradiation have been developed. ${ }^{66-72}$ PAS offers unique sensitivity to vacancy-type defect formations on scales as small as monovacancies. In one example, Tsuchida et al. used in situ PAS to investigate the enhanced radiation tolerance of nanocrystalline $\mathrm{Ni}$ simultaneously implanted with 


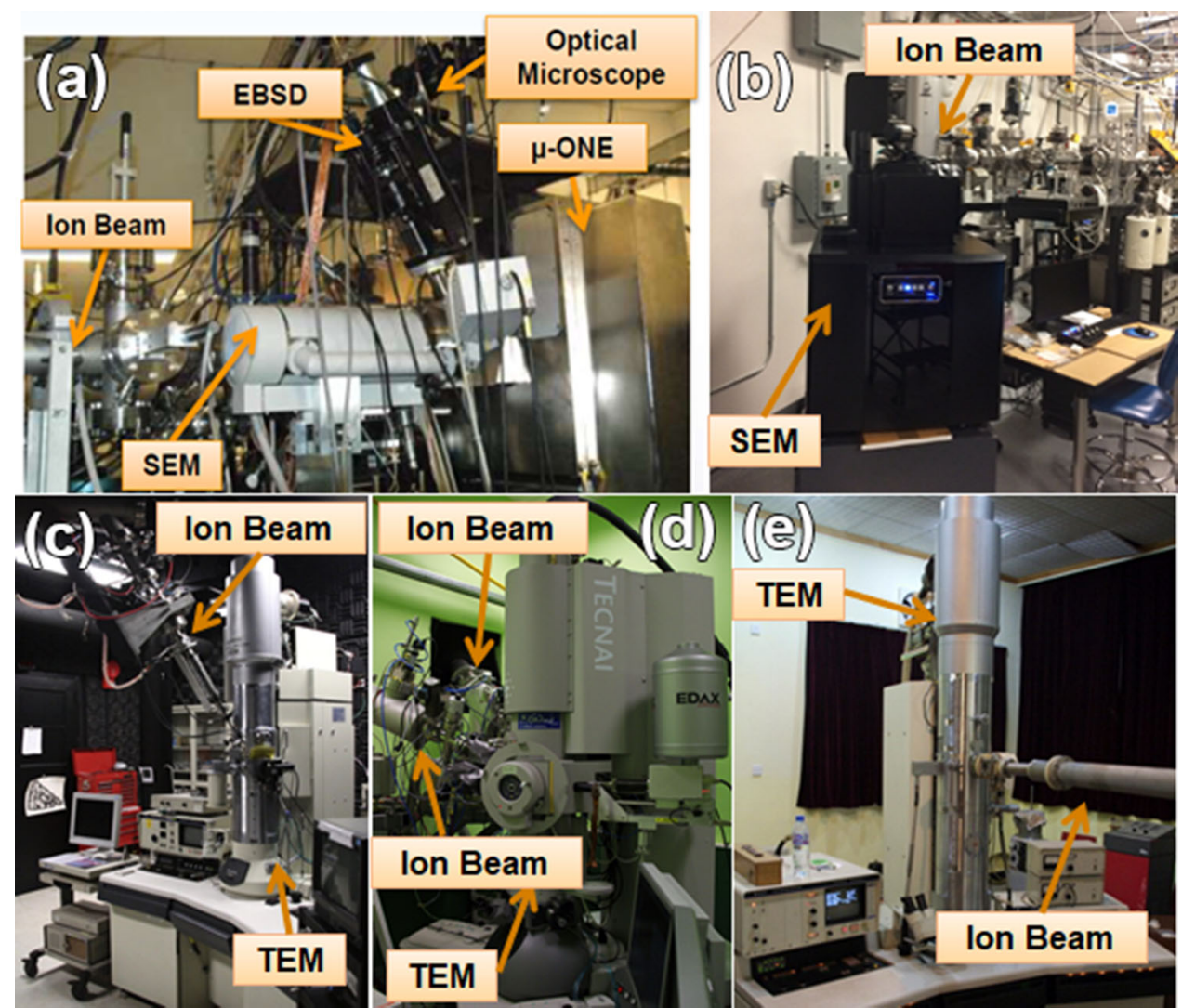

Fig. 3. In situ ion irradiation SEMs: (a) The micro-ONE system at Sandia National Laboratories, (b) the in situ ion irradiation SEM (I ${ }^{3}$ SEM) at Sandia National Laboratories. In situ ion irradiation TEMs: (c) the Hitachi H-9000NAR at Argonne National Laboratory, USA, (d) the FEI Tecnai200 at the JANNuS facility at CSNSM, France, and (e) the Hitachi $\mathrm{H}-800$ at Wuhan University, China, reprinted with permission from Ref. 28.

light ions. ${ }^{73}$ However, challenges remain in quantitively recovering defect information (such as specific vacancy cluster size and density) through the indirect responses measured using PAS. Nonetheless, advanced facilities for in situ PAS are under development in several countries. ${ }^{72}$

\section{X-ray Characterization Techniques}

X-ray-based characterization tools are utilized to characterize material composition, phase, and strain evolution under ion irradiation. X-ray Photoelectron Spectroscopy (XPS) is a surface-sensitive characterization technique used to track the bonding states and compositions of the first few layers of surface atoms of materials. ${ }^{74}$ In situ XPS facilities have been developed for monitoring compositional changes in the first layer of atoms that drive surface responses without exposure to air. ${ }^{75-77}$ Multicomponent semiconductor materials can undergo surface nanostructuring driven by irradiation-induced segregation. The surface chemistry evolution of GaSb and CdZnTe under low energy ion bombardment have been analyzed with in situ XPS, showing a trend towards elemental segregation. ${ }^{78-80}$ Figure $5 \mathrm{a}-\mathrm{b}$ shows the Interaction of Materials with Particles and Components Testing (IMPACT) facility designed for in situ investigations of material surfaces under ion irradiation, and corresponding in situ, in vacuo XPS data of GaSb under ion bombardment, showing the surface compositional changes that can occur in multi-component semiconductors under ion irradiation. In situ Grazing Incidence x-ray Scattering (GISAXS) has also been developed for analyzing the nanostructure evolution of semiconductor materials under irradiation. ${ }^{78,81}$

Beyond semiconductors, the evolution of plasmafacing materials in future nuclear fusion reactors must be deciphered to ensure safe and continued core reactor performance. In vacuo XPS systems have been developed for characterizing the surface composition of materials exposed to fusion plasmas. ${ }^{77,82,83}$ These methods are useful for characterizing near-surface features due to the probing depth of x-rays used, which is vital for surface nanostructuring or preferential sputtering for materials that are altered at the surface by ion irradiation. However, higher energy ions or materials susceptible to deeper damage require other characterization tools.

X-ray Diffraction (XRD) allows one to probe beyond the first layer of atoms to understand both composition and crystal structure. In situ XRD systems for monitoring materials evolution in realtime under ion bombardment have been developed by Grygiel. ${ }^{84}$ Initial studies have investigated the amorphization kinetics of $\mathrm{SrTiO}_{3}$ under 

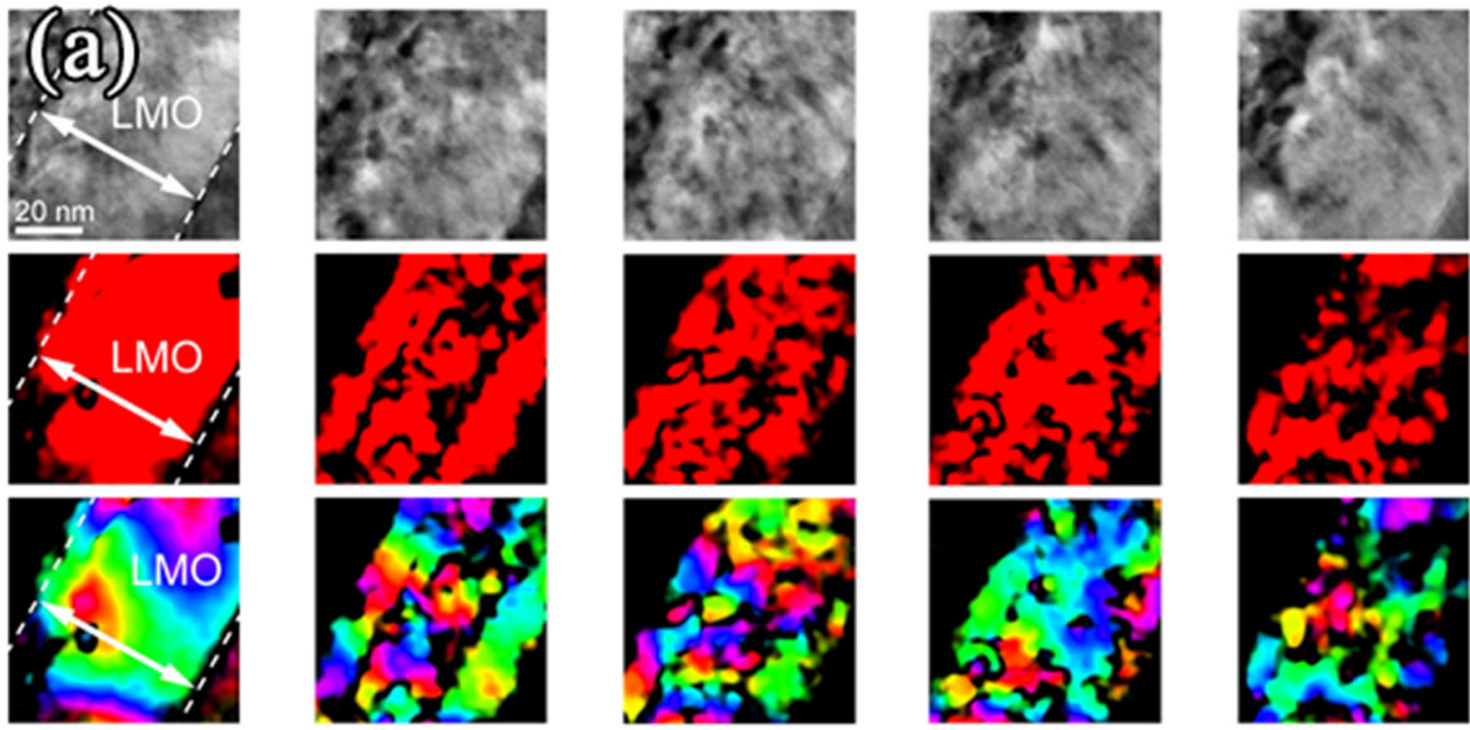

Dose
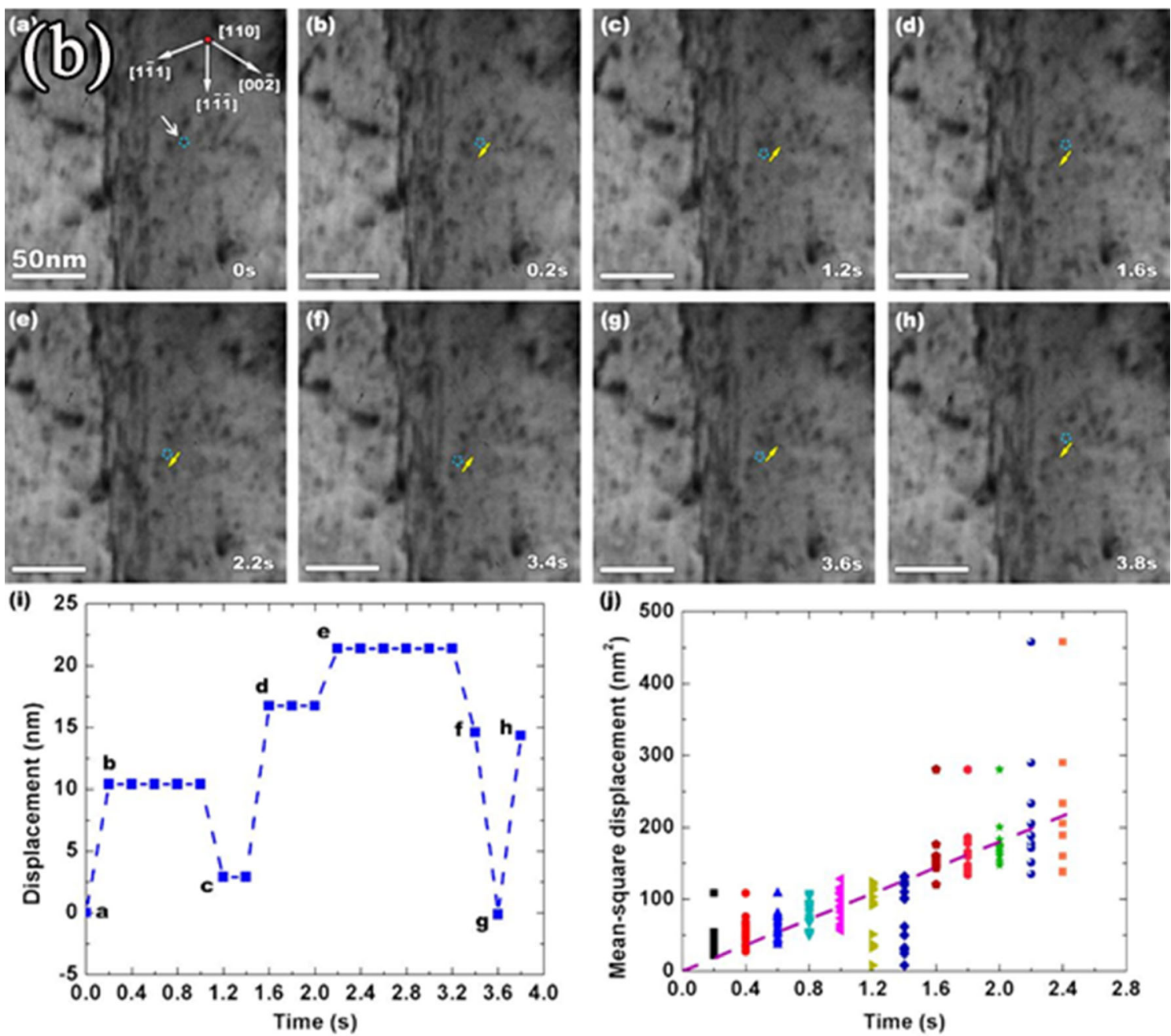

Fig. 4. In situ observation of heavy ion irradiation in various materials showcasing the ability for in situ TEM irradiation to probe dynamic behavior, such as (a) percolation of disorder at oxide interfaces under Au irradiation, reprinted with permission from Ref. 48 and (b) the motion of dislocations in $\mathrm{Cu}$ under $\mathrm{Cu}$ irradiation, reprinted with permission from Ref. 49. 

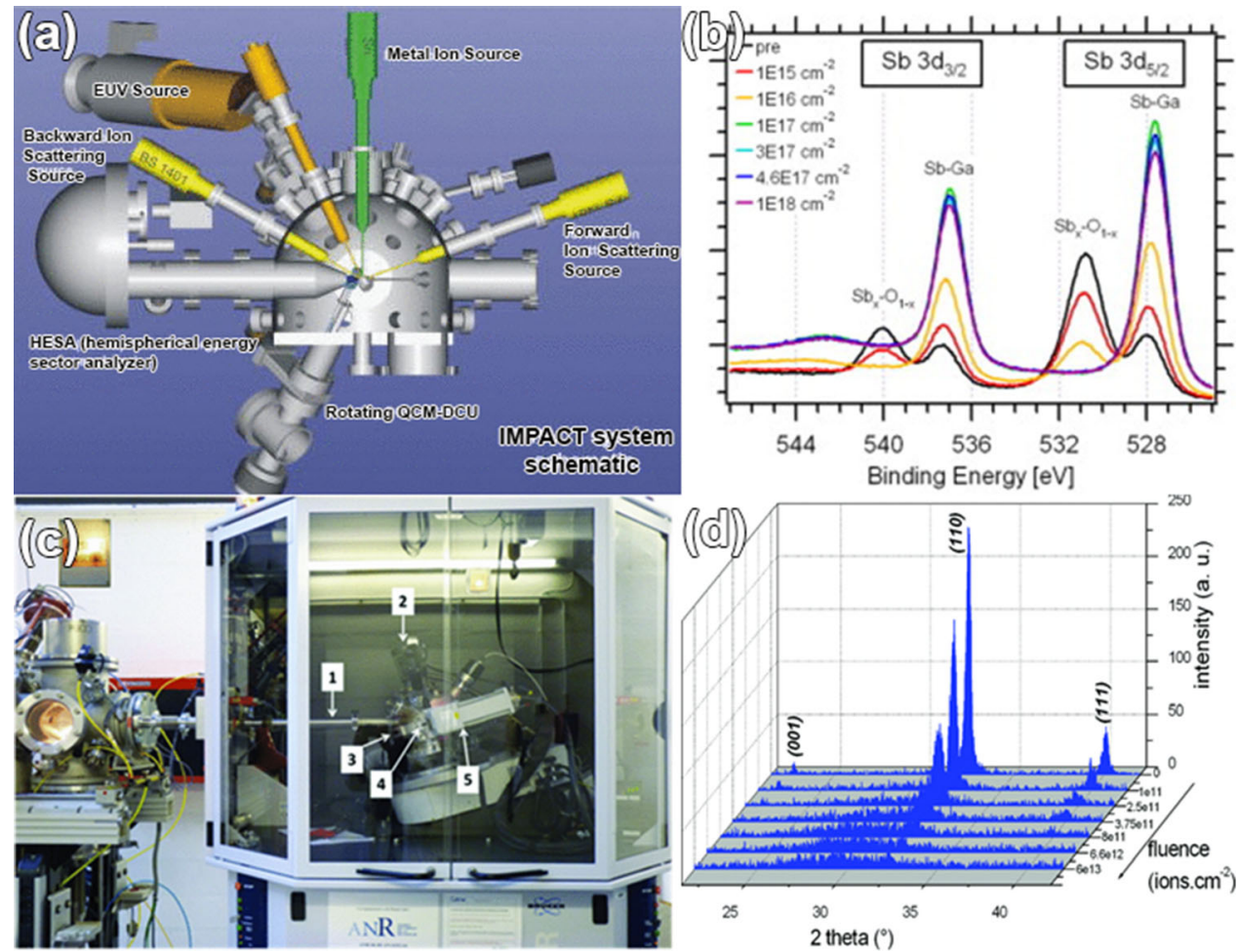

Fig. 5. (a) In situ XPS facility (IMPACT at Purdue University, USA) for tracking surface composition of materials, reprinted with permission of AIP Publishing from Ref. 75 (b) GaSb under ion irradiation, tracking surface composition progression through ion fluence reprinted with permission from Ref. 79. (c) in situ XRD set-up (ALIX facility at CEA, France) used for studying the crystallinity and composition of bulk materials during simultaneous irradiation, including deciphering the impact of irradiation on the crystallinity of $\mathrm{SrTiO}_{3}$ (d), reprinted with permission of AIP Publishing from Ref. 84.

simultaneous ion bombardment, with minimal loss in signal. The ALIX facility offers the first ability to probe materials crystallinity evolution and composition in real-time with XRD. Figure $5 c-d$ shows the experimental design of the ALIX facility, with an ion beam interfacing into and x-ray diffractometer (c) and resulting diffraction patterns of $\mathrm{SrTiO}_{3}$ under ion bombardment (d) showing a loss in crystallinity as the irradiation fluence progresses.

\section{Optical-Infrared Characterization Techniques}

Imaging of materials with electron beams and tracking composition with x-ray techniques allows for material microstructure to be monitored in realtime. Optical- and laser-based techniques can also be used for material structure monitoring to indirectly probe the ion-irradiation induced changes. These techniques can be deployed in situ with ion irradiation as they are non-destructive and are not affected by the electro-magnetic fields needed to manipulate ion beams. Common techniques for understanding ion effects on materials include luminescence, ${ }^{85}$ reflectivity, ${ }^{86,87}$ and ellipsometry. ${ }^{88}$ In situ monitoring of materials has even been used to detect single ion strike events in materials through ion beam induced luminescence (ionoluminesence). ${ }^{89}$
Ellipsometry is commonly used to evaluate the properties of thin films, probing the near-surface morphology and roughness of materials. Typically used to evaluate thin films following fabrication, ellipsometry has been interfaced for in situ monitoring of thin film growth. ${ }^{90}$ Recent studies have integrated ellipsometry into ion-irradiation facilities to track the structure of materials under ion bombardment. ${ }^{8,91}$ Hada et al. evaluated surface damage evolution of thin films under Ar ion bombardment using ellipsometry, to show measurements of sputtering yields via analysis of resulting film thicknesses during synergistic ion bombardment. ${ }^{88}$ Advancing beyond thin film thickness measurements, Wong et al. monitored the structure of bulk tungsten under He irradiation using in situ ellipsometry, offering a non-destructive method for evaluating the surface roughness of $\mathrm{W}$ under high temperature He irradiation to understand the surface nanostructure (fuzz) dynamics that may evolve in nuclear fusion plasma-facing materials. ${ }^{91}$

Optical reflectivity is a common technique for analyzing material evolution, as the reflectivity can depend on surface damage, crystallinity, or phase of a material. Reflectivity is especially important for the use of metallic mirrors in extreme environments where they may be exposed to high fluences of low energy ion bombardment. In situ reflectivity is a useful diagnostic tool for materials destined for use 
in these environments and can be used for materials down-selection or design enhancement. Urabe et al. and Ono et al. evaluated the optical reflectivity of Mo and steel under He irradiation, showing that the real-time deterioration of reflectivity is intense and depends on the ion energy and changes with dose $^{87,92}$ In addition, reflectivity can be employed for in situ monitoring of phase change dynamics in phase-change materials, such as germanium-antimony-tellurium (GST). ${ }^{3,93}$ Figure 6 outlines the key experimental facilities and results for optical spectroscopies of ion-material interactions.

Ion-irradiation-induced luminescence is a nonthermal, photon emission technique that can be used to probe the dynamic responses of damage and relaxation in ceramics and glasses when light is emitted as ions hit a target material. The performance of ceramics and glasses where ionoluminescence occurs under irradiation warrants investigation as the absorption and emission properties can be influenced by point defects, by phase changes or crystallization, by local ordering, and by chemical doping. Therefore, the dynamic evolution of photoemission under simulated irradiation environments may be used as an indicator of irradiation effects in many materials and is particularly important for understanding the dynamic evolution and failure of scintillator devices. Integrated facilities for monitoring of materials evolution have been developed with multiple optical spectroscopy techniques ${ }^{94}$ and dedicated luminescence characterization. $^{95}$ Although luminescent techniques offer limited spatial resolution, they are useful for monitoring defects in the near-surface immediately following ion strikes in materials of many types.

Nagata et al. utilized in situ ionoluminesence of zirconia under $\mathrm{H}$ and $\mathrm{He}$ irradiation to non-destructively probe the evolution of damage. Via in situ monitoring, the role of oxygen deficiencies within the zirconia matrix on $\mathrm{H}$ and $\mathrm{He}$ trapping was elucidated. ${ }^{96}$ Srivastava et al. investigated the role of ion species on the damage evolution within zirconia, utilizing ionoluminesence and showed clear differences in the luminescence response during $\mathrm{Si}$ or $\mathrm{He}$ ion bombardment were observed, therefore demonstrating incident particle discrimination. ${ }^{97}$ Saavedra et al. utilized similar techniques to understand the radiation damage in fused silica under various irradiation conditions. ${ }^{98}$ The ionoluminesence spectra collected during in situ monitoring showed an ion dose and species dependence, indicating the high dose He irradiation is required to incur similar damage as low dose $\mathrm{O}$ and $\mathrm{Si}$ irradiation. Sunitha et al. applied in situ ionoluminescence monitoring to a rare-earth-activated phosphor, $\mathrm{CaSiO}_{3}: \mathrm{Dy}^{3+}$, under $\mathrm{Si}$ ion irradiation to
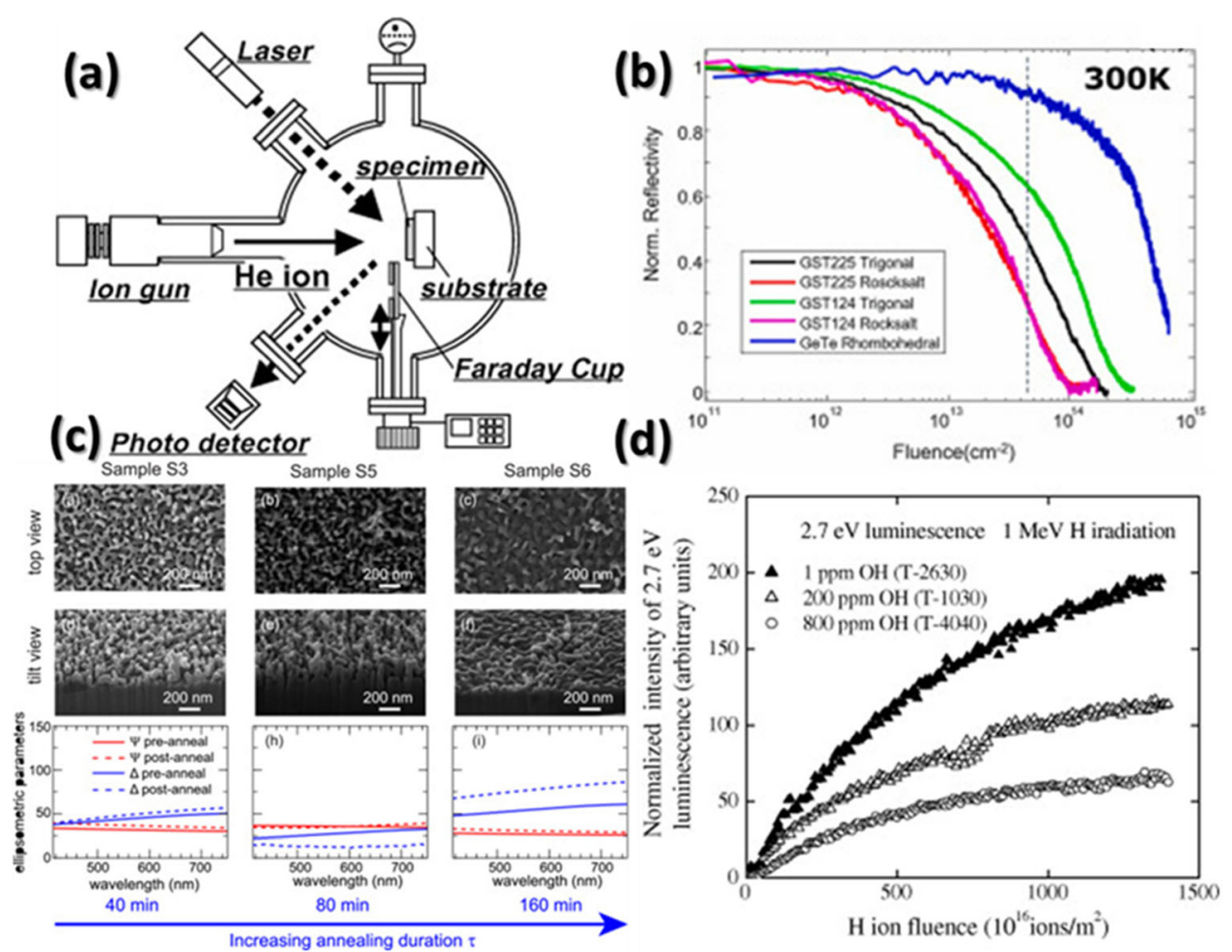

Fig. 6. (a) Experimental set-up for investigating in situ reflectivity of materials under He irradiation, reprinted with permission from Ref. 87. (b) Reflectivity of GST under ion bombardment to correlate ion-induced phase changes with reflectivity, reprinted with permission from Ref. 3. (c) In situ monitoring of W surfaces with ellipsometry to understand the evolution of He irradiation induced surface morphology development, reprinted with permission from Ref. 91 under the terms of the Creative Commons Attribution-NonCommercial-No Derivatives License (CC BY NC ND). (d) In situ ion-induced luminescence intensity of fused silica, showing the impact of bonding states, and the temporal resolution of in situ studies, reprinted with permission from Ref. 96. 
generate an understanding of the impacts of ion irradiation on the surface bonding and resulting phosphor behavior. ${ }^{99}$

Raman spectroscopy is laser-based technique that can be used to track material composition and structure in inorganic materials (mostly non-metallic) through the inelastic scattering of incident photons from crystal vibrational modes. It is versatile, rapid, and non-destructive, making it ideal for in situ monitoring of materials under ion bombardment. Raman studies are particularly suited to ceramic materials under irradiation, which can undergo compositional and phase changes through the accumulation of defects modifying their Raman signatures. Large-scale experimental facilities for in situ monitoring of materials under ion irradiation with Raman spectroscopy have been designed and implemented, most notably in France. The JANNuS facility, developed by Beck et al., has been used to monitor irradiation-induced damage through many characterization tools including an in situ Raman spectrometer interfaced with an ion accelerator. ${ }^{94}$ The schematic of an experimental facility developed for in situ Raman spectroscopy measurements is shown in Fig. 7a, with Fig. 7b showing initial results detailing the loss of order in $6 \mathrm{H}-\mathrm{SiC}$ under ion irradiation. ${ }^{100}$

Miro et al. utilized in situ Raman spectroscopy to study defect accumulation and amorphization in materials with nuclear reactor applications, including $\mathrm{SiC}, \mathrm{ZrO}_{2}$, and $\mathrm{B}_{4} \mathrm{C} .{ }^{100}$ This work showed that tracking Raman-active phonon modes allows new insight into phase changes, amorphization, and dynamics of irradiation-induced degradation. Significant work has focused on characterizing $\mathrm{UO}_{2}$ in situ in simulated applications environments using Raman spectroscopy. ${ }^{101-103}$ Canizares et al. developed a portable in situ Raman spectroscopy diagnostic tool and explored the surface dissolution of $\mathrm{UO}_{2}$ under combined $\mathrm{He}^{2+}$ irradiation and $\mathrm{H}_{2} \mathrm{O}$ exposure. ${ }^{101}$ In similar studies, the performance of
$\mathrm{UO}_{2}$ in an $\mathrm{Ar} / \mathrm{H}_{2}$ environment with simultaneous He irradiation have been studied. ${ }^{102}$ Later, Gutierrez et al. investigated $\mathrm{UO}_{2}$ specimens using in situ Raman spectroscopy under heavy ion irradiation using the JANNuS platform. ${ }^{104}$ They showed that no amorphization was observed in this nuclear fuel material at very high damage levels, but that the dynamic observation of defect evolution as measured by Raman differed significantly compared to that observed using IBA. This study in particular highlights the need for multiple dynamic methods capable of capturing in situ evolution during damage accumulation. For the sake of safety and reliability, multiple methods should be used to confirm material dynamics observed initially using one preferred method if possible. Additional in situ Raman experiments have been carried out in other facilities on diamond during noble gas implantation to provide insight into the behavior of carbonaceous materials in astrophysical environments. ${ }^{105}$

\section{IN SITU PROPERTIES CHARACTERIZATION TOOLS}

Methods used to directly monitor microstructural evolution during ion bombardment, like those discussed above, are key to developing a fundamental understanding of structural and chemical defect generation in many material systems. However, it is the effects of these defects on material performance (strength, thermal conductivity, etc.) that are the limiting factors in material deployment in extreme environments. These performance properties dictate when and how often materials will fail to meet engineering criteria. Understanding when these failures will occur via structure-property correlations is the ultimate goal of studying and understanding the defects and microstructures formed under radiation extremes. While much success has been demonstrated in the last several decades in gaining this mechanistic understanding through in situ microstructure monitoring, more recently
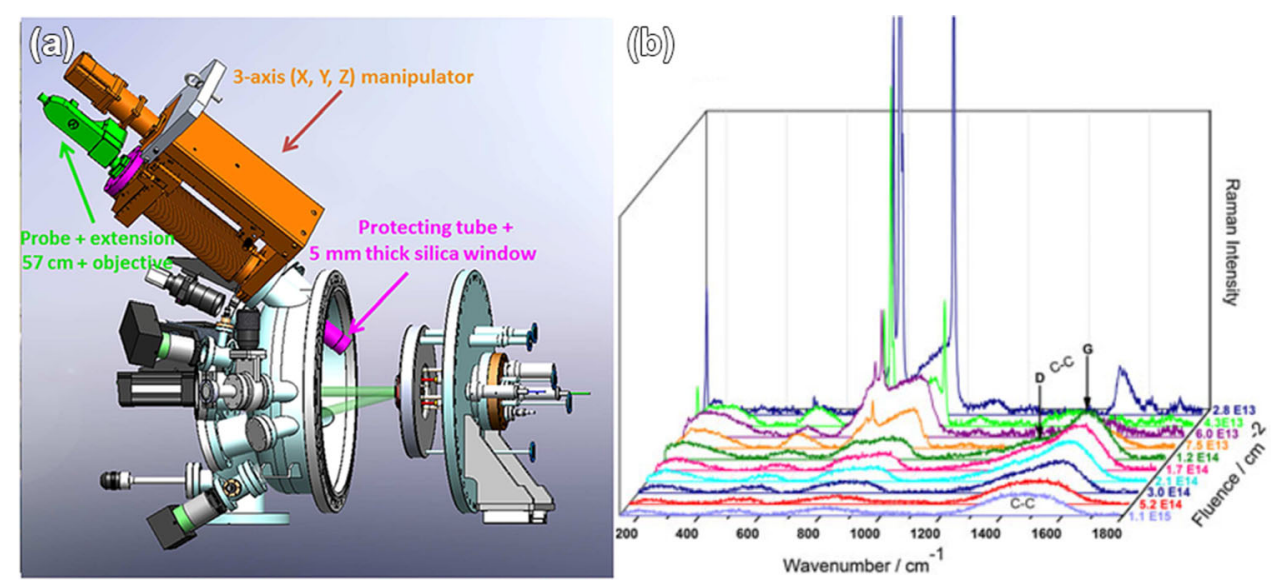

Fig. 7. (a) Schematic of Raman spectroscopy facility designed for in situ investigations of materials under simultaneous ion bombardment. (b) Progression of in situ Raman spectroscopy spectra of $6 \mathrm{H}-\mathrm{SiC}$ during simultaneous ion bombardment showing the dynamics of amorphization, reprinted with permission from Ref. 100. 
new areas of focus have emerged, that seek to target some (or any) of the performance characteristics of materials directly during ion beam irradiation.

These in situ property-focused techniques bear several stringent requirements that limit what types of material properties may be accessed. Fundamentally, methods being used to test performance in situ must not themselves induce changes in microstructure in the materials being subject to external stimuli. It has therefore been of paramount importance to designers of in situ property testing methods to rely on non-destructive methods which are able to interrogate performance without the probe itself serving as an external stimulus.

The set of in situ property test methods with the longest history have been electrical in nature. Such electrical-based probes can be used to directly measure the performance of semiconducting materials and devices ${ }^{106-108}$ or to indirectly use characteristics such as resistivity to infer irradiationdriven changes in microstructure, phase, etc. ${ }^{109-111}$ More recently, laser-based photoacoustic techniques have been deployed to measure thermoelastic properties directly during ion irradiation. ${ }^{112,113}$ Contactbased ultrasonic techniques have also been deployed in ion beam and other radiation environments to observe changes in elasticity and detect irradiationinduced events through acoustic emission, but applications of these methods have been narrow so far. ${ }^{114,115}$

Before discussing each of these classes of experiments in turn, we note that by targeting performance characteristics directly, these methods all capture the integrated effects of defect accumulation and microstructure evolution across all defect sizes from the nanoscale to the microscale. While methods such as in situ microscopy must by nature be targeted at one primary length scale of interest (SEM vs. TEM for example), methods which capture material properties directly will integrate the effects of defects at all scales as long as the representative sampling volume remains larger than the scale of individual defects. ${ }^{116}$ The capability to capture defect effects across all sizes, down to the mono-vacancy or -interstitial level, becomes especially important when seeking to measure transient populations of defects that would be present during system operation, a power-generating nuclear reactor or in-flight satellite for example, but which may not be captured through ex situ property testing once active defect generation is stopped.

\section{In Situ Optical/Infrared Spectroscopy}

Of possible methods to record thermophysical material properties, laser-based photothermal or photoacoustic methods have been identified as some of the most promising to deploy as in situ ion irradiation tools. A variety of these methods have been used to study ion irradiation effects ex situ including time domain thermoreflectance (TDTR), ${ }^{117}$ spatial domain thermal reflectance (SDTR), ${ }^{118}$ and laser-based resonant ultrasound spectroscopy. ${ }^{119}$ Each of these methods share characteristics of being all-optical, non-destructive measurements conducted without contact with the specimen of interest. However, to date, the most expansive use of in situ laser-based thermophysical property measurement techniques has come from the application of transient grating spectroscopy (TGS). ${ }^{115,116,119-122}$ All of these photothermal and photoacoustic methods fall into the category of pump-probe techniques where some form of laser excitation is provided to induce a response in the material in question. Following excitation, a probing laser detects the material response through physical displacement, the thermoreflectance effect, or some combination of both.

Dennett et al. have deployed in situ ion irradiation transient grating spectroscopy ( ${ }^{3}$ TGS) on an ion beamline, combining a long working distance free-space TGS optical experiment with a $6 \mathrm{MV}$ tandem ion accelerator. ${ }^{120} \mathrm{~A}$ schematic of the sample environment used for $\mathrm{I}^{3}$ TGS is shown in Fig. 8a. This system can track thermal conductivity and near-surface elastic modulus in real time during ion beam exposure. To date a majority of studies conducted using the ${ }^{3}$ TGS beamline have focused on the detection of volumetric swelling as a result of high-temperature ion irradiation. Swelling as indicated through an initial increase in surface acoustic wave (SAW) velocity due to interstitial clusters, followed by a turnover and reduction due to porosity generation was observed in situ during $\mathrm{Ni}$ ion irradiation of pure, single crystal Ni. ${ }^{120}$ More recently, a series of in situ irradiation experiments on Ni-based complex concentrated solid solution alloys has explored the relative void swelling response of increasingly chemically-disordered materials. ${ }^{116}$ For alloys such as NiCoCr where the ultimate void size remains small, in situ TGS experiments are able to determine the onset of volumetric void swelling through changes in elastic properties before these voids would be easily countable using standard, post-irradiation STEM.

The unique insight available through in situ property monitoring using TGS is highlighted in Fig. 8b. Here, a polycrystalline, refractory multiprinciple element alloy (rMPEA) with composition $30 \mathrm{Mo}-24 \mathrm{Nb}-23 \mathrm{Zr}-13 \mathrm{Cr}-7 \mathrm{Al}-4 \mathrm{Ta}$, was exposed to 10 $\mathrm{MeV} \mathrm{Si}{ }^{2+}$ ions at $450^{\circ} \mathrm{C}$. The target dose level for this experiment was $\sim 100 \mathrm{dpa}$. However, after only $31 \mathrm{dpa}$, the ion beam experienced an unexpected failure. As evidenced by the evolution in SAW velocity during this initial irradiation period, the effective elastic modulus rapidly decreased with irradiation, reaching a steady state around $15 \mathrm{dpa}$. When active defect generation ceases, the temperature remains stable at $450^{\circ} \mathrm{C}$, promoting defect annealing. This annealing is evident in a gradual increase in the SAW velocity, which approaches 

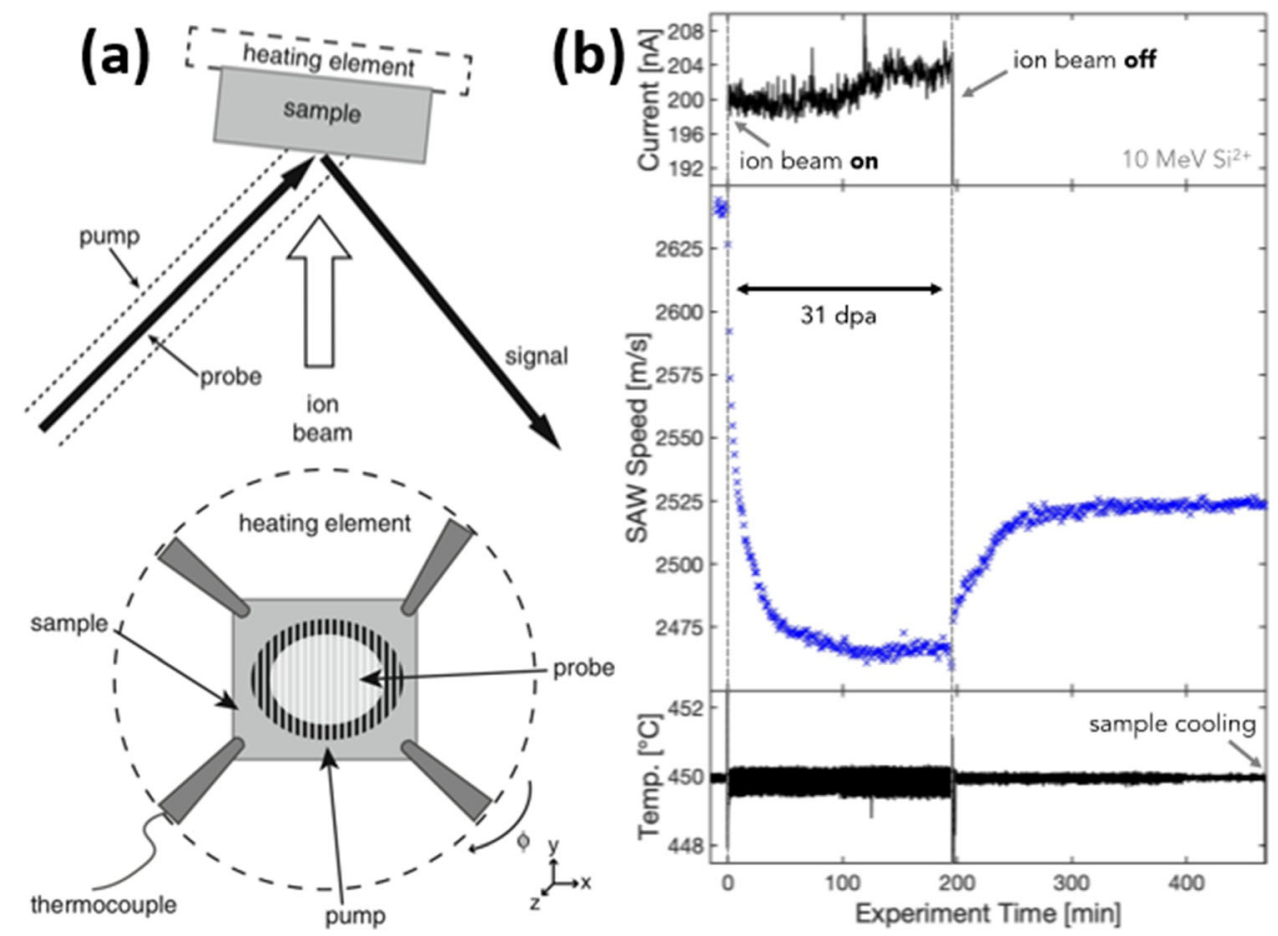

Fig. 8. (a) Experimental arrangement for in situ ion beam irradiation with transient grating spectroscopy thermoelastic property monitoring, reprinted with permission from Ref. 115. (b) Example $\mathrm{I}^{3} \mathrm{TGS}$ experimental record for high temperature irradiation of a refractory multi-principle element alloy with $10 \mathrm{MeV} \mathrm{Si} \mathrm{ions,} \mathrm{showing} \mathrm{the} \mathrm{continuously-recorded} \mathrm{ion} \mathrm{beam} \mathrm{current,} \mathrm{the} \mathrm{TGS-measured} \mathrm{surface} \mathrm{acoustic} \mathrm{wave} \mathrm{(SAW)}$ velocity, and the surface-measured bulk sample temperature. Rapid elastic softening as evidenced by the decrease in SAW velocity during irradiation is observed via non-destructive methods.

another steady state. While on paper a failed experiment, the continuous record of thermoelastic material properties is nevertheless able to offer dynamic information with respect to the dose necessary to reach defect saturation and the time necessary to anneal those defects which are recoverable. All of this detail would otherwise be unavailable in a traditional PIE on bulk specimens.

\section{In Situ Electrical Property Characterization}

Materials used in electronic devices can have their properties and performance tailored via ion irradiation or may be used in extreme environments and subject to irradiation during operation. The evolution of electronic materials under irradiation can be used to validate device performance under simulated operational environments or determine when properties are precisely tuned for the desired application. Deploying in situ resistivity and I-V curve monitoring tools offers the opportunity to probe the dynamics of electronic device failure, ${ }^{107}$ monitor phase transformations in complex materials, ${ }^{123}$ or identify critical doses resulting in changes in superconductivity. ${ }^{109}$

Through in situ monitoring of I-V curves, device performance or tailoring of electronic barriers can be interrogated. Baranwal et al. investigated the impacts of swift heavy ions on metal-semiconductor interfaces of diodes to offer insights into controlling the Schottky barrier height through ion irradiation. ${ }^{106}$ Praveen et al. studied the effects of ion irradiation of Si-Ge transistors to show that oxygen irradiation induced more degradation of device performance than boron irradiation. ${ }^{107}$ Tracking resistivity can also offer a non-destructive evaluation of material changes under irradiation, through defect introductions or phase changes. The dynamic evolution of resistivity of GaAs and $\mathrm{Si}$ crystals under ion irradiation has been tracked in situ to decipher the effects of electronic and nuclear stopping. ${ }^{108,111}$ High temperature superconductors may be used in future nuclear fusion reactors and exposed to radiation; however, changes in their performance in irradiation conditions remains a largely open question. Borges da Costa et al. used in situ resistivity measurements of $\mathrm{NiAl}$ films at 77 $\mathrm{K}$ under Ar irradiation to show dynamic increasing and decreasing resistivity as fluence progresses. ${ }^{109}$ Similarly, Marwick et al. and Ovchinnikov et al. showed changes in resistivity of complex superconducting alloys attributed to phase transformations and order-disorder transitions at critical, specific doses that would otherwise be inaccessible or unidentifiable with solely ex situ monitoring. ${ }^{110,123}$ 


\section{In Situ Mechanical Testing}

Interrogating mechanical properties of materials under ion irradiation allows the degradation and failure of materials to be understood taking an engineering approach, moving beyond simple imaging and towards correlating microstructural evolution with dynamical property changes. While accessing mechanical properties non-destructively (elasticity) the strains remain small enough that effectively no irreversible change is caused by the presence of the probe. An additional class of radiation-accelerated dynamics has been studied through the use of in situ creep experiments on several length scales. ${ }^{124-127}$ While operating outside of the prescription of "no irreversible changes", these creeps tests seek to understand how the additional defects generated through irradiation affect deformation already ongoing, not to interrogate dynamics which are primarily or solely driven by irradiation.

$\mathrm{Xu}$ et al. examined in situ the creep performance of T-91 steel under proton irradiation in a combined end station with mechanical testing on an ion accelerator. ${ }^{124,127}$ Recently, Briggs et al. developed a versatile testing end station for tensile, fatigue, and creep at temperature up to $1000^{\circ} \mathrm{C}$ and ion energies up to $100 \mathrm{MeV}$ to advance understanding of the dynamic deformation response of materials under combined extreme external stimuli. ${ }^{128}$ Small-scale mechanical testing can probe the nanoscale features that drive the bulk material properties. In first of its kind in situ TEM irradiation-induced creep experiments, Dillon et al. showed the evolution of nanoscale $\mathrm{Cu} / \mathrm{W}$ laminate pillars under high energy ion bombardment. ${ }^{125}$ Subsequent experiments have examined the irradiationinduced creep behavior in high entropy alloys and $\mathrm{Zr}$, demonstrating the ability to elucidate fundamental nanoscale mechanical deformation mechanisms that occur during ion irradiation. ${ }^{129,130}$ Figure 9 highlights in situ ion irradiation mechanical characterization facilities in bulk (a) and on the TEM scale (b).

Materials under ion irradiation undergo complex, dynamic processes that can alter the material morphology, composition, structure, and, resultingly, the properties. We have attempted to show that in situ monitoring of materials under ion irradiation is a diverse field offering a wealth of methods to future experiment designers: monitoring microstructures through x-ray spectroscopy and diffraction techniques, electron beam imaging, and laser-based spectroscopies; and monitoring properties through laser-based methods, electrical connections, and bulk and nanoscale mechanical testing. Nonetheless, more and more diverse tools should and are being developed to interrogate material evolution in situ in combined irradiation and external stimuli environments via multiple characterization techniques. Our current and future tools will
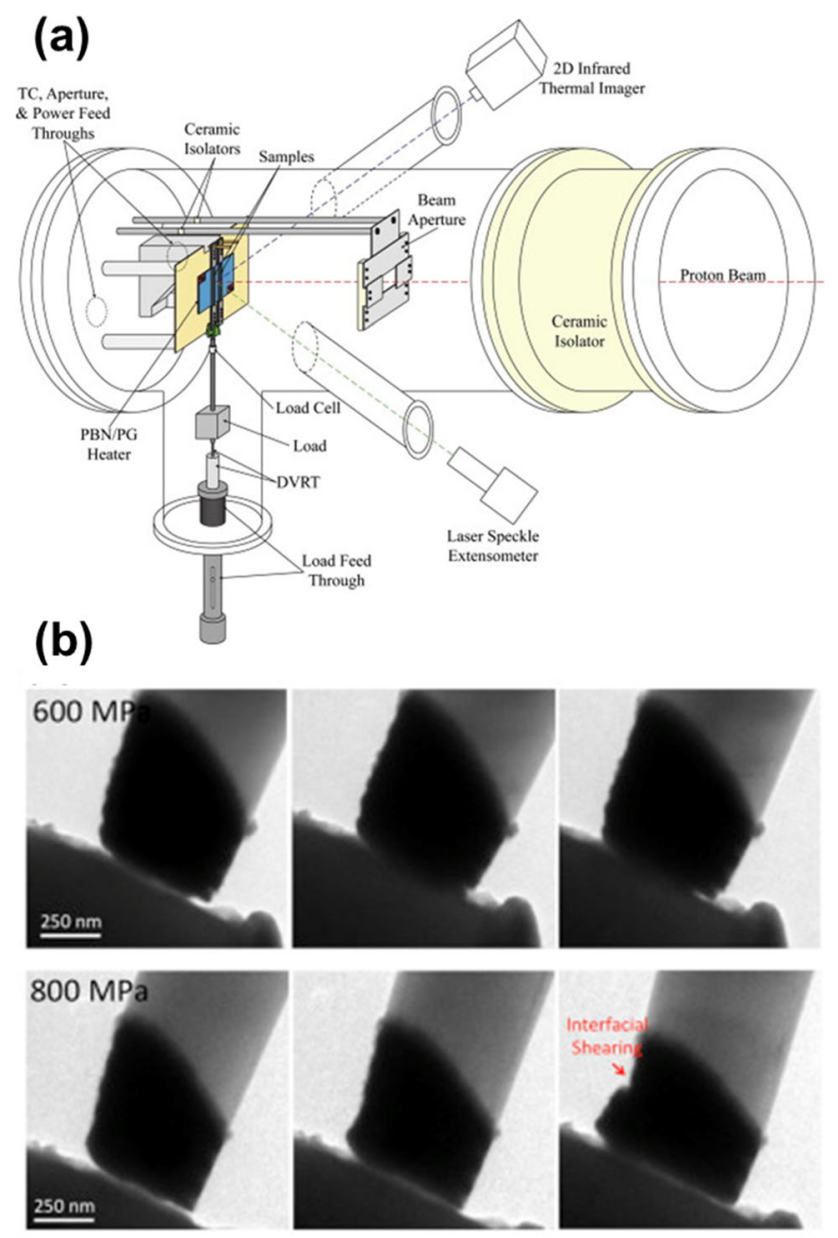

Fig. 9. (a) Experimental design for testing irradiation-induced creep on bulk samples, showing the ion beam, load direction, and bulk sample, reprinted with permission from Ref. 127. (b) TEM micrographs detailing the experimental setup of nanoscale in situ irradiation-induced creep experiments, indicating the nanoindentor and $\mathrm{Cu} / \mathrm{W}$ laminate, and deformation (interfacial shearing mechanisms), reprinted with permission from Ref. 125.

allow a widening field to advance the understanding of materials evolution during the dynamic materialirradiation process.

\section{FUTURE DIRECTIONS}

Through the miniaturization and adaptation of materials characterization techniques and property testing platforms, the scope of materials and irradiation conditions that can be explored in situ has greatly expanded. Through the last few decades, the integration of characterization tools onto ion beam accelerators, as Fig. 10 shows, has enhanced in situ materials monitoring. The future of in situ microstructure monitoring during ion irradiation relies upon the ability to diagnose dynamic material evolution with advanced characterization tools. Recent advances in electron optics have provided unprecedented advances in spatial and temporal 


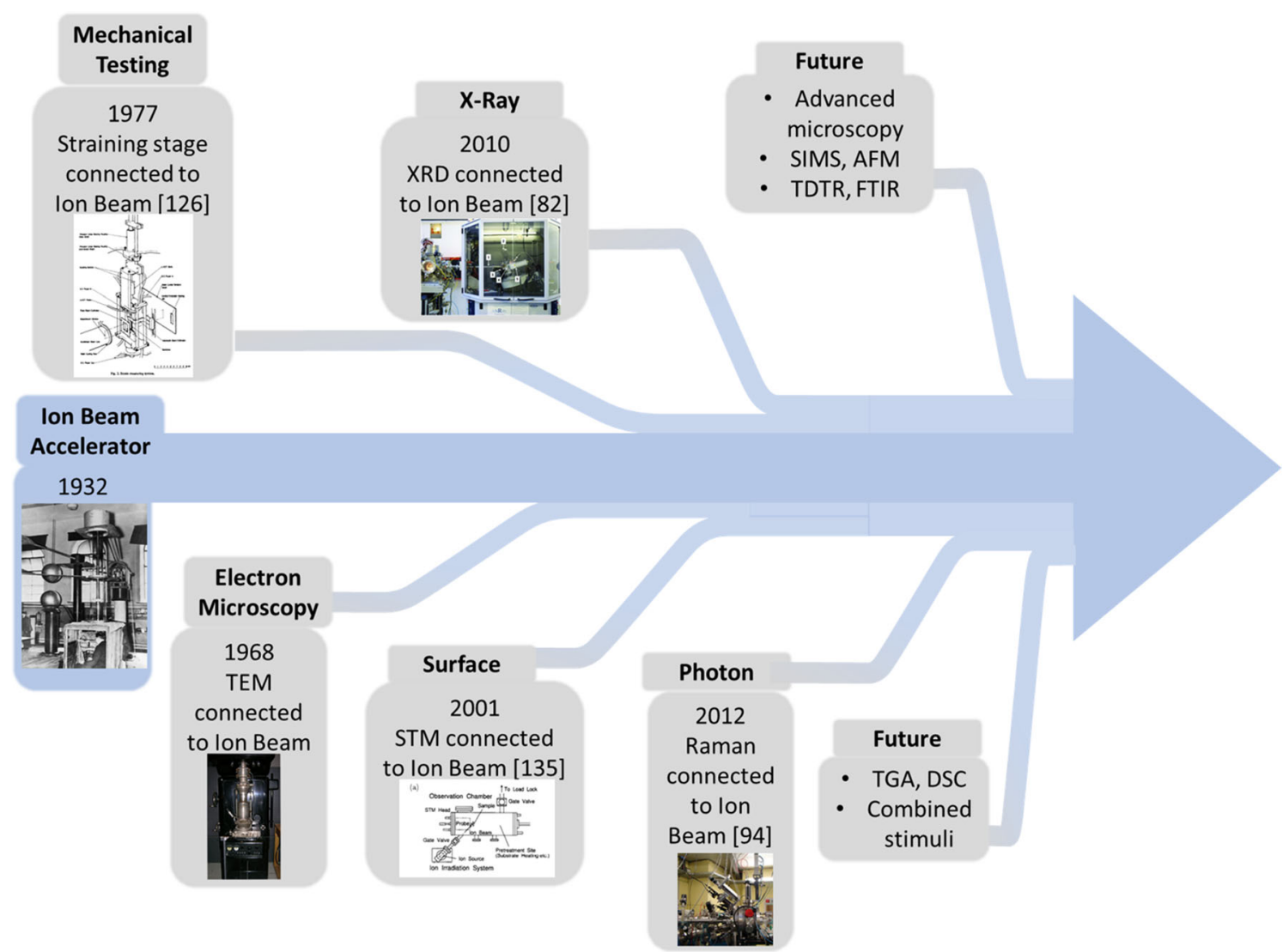

Fig. 10. X-ray, electron, and photon techniques can be combined with ion irradiation for continued investigations of dynamic material processes. Future facilities and experiments will integrate multiple characterization tools in situ for real-time monitoring of material structure and property transients on wide spatial-temporal scales to gain a complete picture of material evolutions, reprinted with permissions from refs Refs. $84,94,126,135$.

resolution as seen in both the dynamic TEM (DTEM) ${ }^{131}$ and Aberration-Corrected TEM (ACTEM) ${ }^{132}$ respectively. If successfully combined with in situ ion bombardment these new capabilities offer nanosecond and sub-angstrom resolution, which can provide new insights into inherently dynamic and atomic-scale processes. In a similar way, the advancements and miniaturization in SEM and other lower energy electron microscopy techniques make them ripe for in situ ion beam integration. Beyond electron microscopy, the evolution of surface composition and structure can continue to be explored via a range of advanced characterization techniques. One can envision characterizing gascovered surfaces via near-ambient pressure XPS, ${ }^{133}$ integrating an ion beam with a synchrotron light source, ${ }^{134}$ re-igniting prior in situ irradiation Scanning Tunneling Microscopy (STM) $)^{135,136}$ and Atom Probe Tomography (APT) studies ${ }^{137,138}$ investigations, and combining multiple IBA techniques with ion accelerators. ${ }^{139}$ Additionally, given careful engineering considerations, in situ characterization with Secondary Ion Mass Spectrometry (SIMS), Atomic Force Microscopy (AFM), and Gas Chromatography Mass Spectrometry (GCMS) can be envisioned.
In situ monitoring of material properties under irradiation will rely on advances of optical spectroscopies, pump-probe techniques, and integrated testing platforms. TDTR techniques have been deployed for in situ monitoring of battery materials thermal conductivity under charge cycling ${ }^{140}$ and can be envisioned to be used for similar characterization for in situ irradiation facilities. Transient thermoreflectance (TTR) has been used to study porosity and consolidation in situ during fabrication of 3-D printed metals and could be envisioned to investigating similar material property evolution under ion irradiation. ${ }^{141}$ Similarly, in situ Fourier Transform Infra-Red Spectroscopy facilities for tracking photocatalysis during fabrication and under visible light and UV irradiation and have been developed ${ }^{142,143}$ and could be adapted into ion accelerators. Recent work showing the sensitivity of differential scanning calorimetry (DSC) and thermal gravitation analysis (TGA) to radiation-induced defects in polymers materials motivate the consideration of combining this type of thermal analysis with in situ ion irradiation. ${ }^{44}$ Finally, in situ angleresolved photoemission spectroscopy has been shown to be a powerful tool in the investigation of electrical properties of bulk specimens and 
heterostructures during synthesis or modification $^{145}$; adding ion-beam processing to the available stimuli could open new opportunities for device optimization.

Figure 10 outlines the history of in situ irradiation characterization facilities, integrating individual characterization tools. However, as Fig. 10 indicates, future in situ characterization facilities will combine analysis techniques and environments for multi-scale transient materials analysis in simulated real-world application environments. For example, in situ irradiation in an Environmental TEMs (ETEM) with a quantitative mechanical stage could explore the combined effects of irradiation, gas environments, and mechanical loads simultaneously. Future ion beam facilities can also combine multiple characterization techniques to offer a more complete picture of the dynamic, multi-scale structure-property evolution of materials under ion irradiation. Investigating the performance of materials under synergistic external stimuli with combined characterization tools will better advance understanding of real-world material performance. Future studies can build upon prior work to advance understanding of the corrosion performance of materials under combined ion irradiation and corrosive environments to test material performance in simulated advanced nuclear reactors. ${ }^{146}$ The only limitations to the widening spatial and temporal scales for the in situ characterization of materials under ion irradiation are one's creativity and the laws of physics.

\section{CONCLUSION}

Ion irradiation is frequently used to change the composition, structure, and properties of materials, from polymers through semiconductors to metals. Ion beam exposure can result in surface modification, local doping, and nanoscale restructuring in a myriad of complex forms. The ability to design novel materials through ion irradiation necessitates material analysis beyond typical post-irradiation characterization, thus, requires in situ techniques to probe the real-time evolution of materials. This brief review highlighted the numerous electron, ion beam, $\mathrm{x}$-ray, optical/IR-based, and mechanical testing techniques that have been developed for in situ monitoring of material structure and property dynamics during ion bombardment. The greatest value of in situ monitoring is the ability to capture transient processes dictating material responses under controlled external stimuli. The ability to perform combined in situ characterization and property monitoring of materials offers a holistic approach to tracking and understanding of material performance in often-complex real-world application environments.

\section{ACKNOWLEDGEMENTS}

The authors would like to thank Drs. K.A. Small, G. Vizkelethy, J. Villone, and Mr. D. Ranke for their assistance with the manuscript. C.A.D. acknowledges support through the INL Laboratory Directed Research and Development Program under U.S. Department of Energy Idaho Operations Office Contract DE-AC07-05ID14517. This work was supported, in part, by the U.S. Department of Energy, Office of Nuclear Energy under DOE Idaho Operations Office Contract DE-AC07-05ID14517 as part of the Nuclear Science User Facilities. This work was performed, in part, at the Center for Integrated Nanotechnologies, an Office of Science User Facility operated for the U.S. Department of Energy (DOE) Office of Science. Sandia National Laboratories is a multimission laboratory managed and operated by National Technology \& Engineering Solutions of Sandia, LLC, a wholly owned subsidiary of Honeywell International, Inc., for the U.S. DOE's National Nuclear Security Administration under Contract DE-NA-0003525. The views expressed in the article do not necessarily represent the views of the U.S. DOE or the United States Government.

\section{CONFLICT OF INTEREST}

The authors declare that they are unaware of any conflict of interest.

\section{OPEN ACCESS}

This article is licensed under a Creative Commons Attribution 4.0 International License, which permits use, sharing, adaptation, distribution and reproduction in any medium or format, as long as you give appropriate credit to the original author(s) and the source, provide a link to the Creative Commons licence, and indicate if changes were made. The images or other third party material in this article are included in the article's Creative Commons licence, unless indicated otherwise in a credit line to the material. If material is not included in the article's Creative Commons licence and your intended use is not permitted by statutory regulation or exceeds the permitted use, you will need to obtain permission directly from the copyright holder. To view a copy of this licence, visit $h$ ttp://creativecommons.org/licenses/by/4.0/.

\section{REFERENCES}

1. J.P. Allain and A. Shetty, J. Phys. D: Appl. Phys. 50, 283002. (2017).

2. P. Sigmund and N.Q. Lam, Kongelige Danske Videnskabernes Selskab Det, Matematisk-Fysiske Meddelelser 43, 255. (1993).

3. S.M.S. Privitera and E. Rimini, Mater. Sci. Semicond. Process. 135, 106087. (2021).

4. J. Zheng, R. Yang, L. Xie, J. Qu, Y. Liu, and X. Li, Adv. Mater. 22, 1451. (2010).

5. P.D. Townsend, J.C. Kelly, and N.E.W. Hartley, Ion implantation, sputtering and their applications, (Academic Press, 1976). 
6. T. Hasebe, S. Nagashima, Y. Yoshimoto, A. Hotta, and T. Suzuki, Nucl. Instrum. Methods Phys. Res. Sect. B 282, 134. (2012).

7. S. Facsko, T. Dekorsy, C. Koerdt, C. Trappe, H. Kurz, A. Vogt, and H.L. Hartnagel, Sci. 285, 1551. (1999).

8. M.J. Baldwin and R.P. Doerner, Nucl. Fusion 48, 035001. (2008).

9. J.S. Williams, Mater. Sci. Eng. A 253, 8. (1998).

10. O. Peña-Rodríguez, J. Olivares, M. Carrascosa, A. GarcíaCabañes, A. Rivera, F. Agulló-López, Optical Waveguides Fabricated by Ion Implantation / Irradiation: A Review, 267 (2012).

11. N. Andrianova, A. Borisov, E. Mashkova, and Y.S. Virgiliev, J. Spacecraft Rockets 48(45), 45. (2011).

12. M.M. Rahman, W.-Y. Chen, L. Mu, Z. Xu, Z. Xiao, M. Li, X.M. Bai, and F. Lin, Nat. Commun. 11, 4548. (2020).

13. P. Hosemann, Rev. Accelerator Sci. Technol. 04, 161. (2011).

14. G.S. Was, R.S. Averback, Comprehensive Nucl. Mater., (Elsevier, Oxford, 2012), pp. 195-221.

15. N. Yao, Focused Ion Beam Systems: Basics and Applications (Cambridge University Press, Cambridge, 2007).

16. D. Gamba, R. Corsini, S. Curt, S. Doebert, W. Farabolini, G. McMonagle, P.K. Skowronski, F. Tecker, S. Zeeshan, E. Adli, C.A. Lindstrøm, A. Ross, L.M. Wroe (2018) Nucl. Instrum. Methods Phys. Res., Sect. A, 909, 480.

17. G.M. Wright, H.A. Barnard, L.A. Kesler, E.E. Peterson, P.W. Stahle, R.M. Sullivan, D.G. Whyte, and K.B. Woller, Rev. Sci. Instrum. 85, 023503. (2014).

18. W.J. Weber, N. Yu, and L.M. Wang, J. Nucl. Mater. 253, 53. (1998).

19. Y. Haddad, L. Delauche, A. Gentils, and F. Garrido, Nucl. Instrum. Methods Phys. Res. Sect. B 435, 25. (2018).

20. B. Breeger, E. Wendler, W. Trippensee, C. Schubert, and W. Wesch, Nucl. Instrum. Methods Phys. Res. Sect. B 174, 199. (2001).

21. S. Thevuthasan, W. Jiang, V. Shutthanandan, and W.J. Weber, J. Nucl. Mater. 289, 204. (2001).

22. G. Velişa, K. Jin, Z. Fan, C. Lu, H. Bei, W.J. Weber, L. Wang, and Y. Zhang, J. Nucl. Mater. 525, 92. (2019).

23. R. Huszank, E. Szilágyi, Z. Szoboszlai, and Z. Szikszai, Nucl. Instrum. Methods Phys. Res. Sect. B 450, 364. (2019).

24. M. Hayashi, M. Matsuda, T. Asozu, M. Sataka, M. Nakamura, and A. Iwase, Nucl. Instrum. Methods Phys. Res. Sect. B 314, 176. (2013).

25. G. Vizkelethy, B.L. Doyle, and F.L. McDaniel, Nucl. Instrum. Methods Phys. Res. Sect. B 273, 222. (2012).

26. R.F. Egerton, P. Li, and M. Malac, Micron 35, 399. (2004).

27. P. Hoffmeyer and R.B. Hanna, Wood Sci. Technol. 23, 211. (1989).

28. J.A. Hinks, Nucl. Instrum Methods Phys. Res. Sect. B 267, 3652. (2009).

29. J.A. Hinks, J. Mater. Res. 30, 1214. (2015).

30. C. Du, S. Jin, Y. Fang, J. Li, S. Hu, T. Yang, Y. Zhang, J. Huang, G. Sha, Y. Wang, Z. Shang, X. Zhang, B. Sun, S. Xin, and T. Shen, Nat. Commun. 9, 5389. (2018).

31. M. Li, M.A. Kirk, P.M. Baldo, D. Xu, and B.D. Wirth, Philos. Mag. 92, 2048. (2012).

32. C. Parkin, M. Moorehead, M. Elbakhshwan, J. Hu, W.-Y. Chen, M. Li, L. He, K. Sridharan, and A. Couet, Acta Mater. 198, 85. (2020).

33. O. El-Atwani, E. Esquivel, E. Aydogan, E. Martinez, J.K. Baldwin, M. Li, B.P. Uberuaga, and S.A. Maloy, Acta Mater. 165, 118. (2019).

34. K.Y. Yu, C. Sun, Y. Chen, Y. Liu, H. Wang, M.A. Kirk, M. Li, and X. Zhang, Philos. Mag. 93, 3547. (2013).

35. W.S. Cunningham, K. Hattar, Y. Zhu, D.J. Edwards, and J.R. Trelewicz, Acta Mater. 206, 116629. (2021).

36. O. El-Atwani, J.E. Nathaniel, A.C. Leff, K. Hattar, and M.L. Taheri, Sci. Rep. 7, 1836. (2017).

37. P.D. Edmondson, K.J. Abrams, J.A. Hinks, G. Greaves, C.J. Pawley, I. Hanif, and S.E. Donnelly, Scr. Mater. 113, 190. (2016).
38. N.J. Briot, M. Kosmidou, R. Dingreville, K. Hattar, and T.J. Balk, J. Mater. Sci. 54, 7271. (2019).

39. C. Sun, M. Song, K.Y. Yu, Y. Chen, M. Kirk, M. Li, H. Wang, and X. Zhang, Metall. Mater. Trans. A 44, 1966. (2013).

40. Y. Chen, J. Li, K.Y. Yu, H. Wang, M.A. Kirk, M. Li, and X. Zhang, Acta Mater. 111, 148. (2016).

41. J. Li, C. Fan, J. Ding, S. Xue, Y. Chen, Q. Li, H. Wang, and X. Zhang, Sci. Rep. 7, 39484. (2017).

42. C. Sun, D. Bufford, Y. Chen, M.A. Kirk, Y.Q. Wang, M. Li, H. Wang, S.A. Maloy, and X. Zhang, Sci. Rep. 4, 3737. (2014).

43. C.J. Ulmer, W.Y. Chen, D.E. Wolfe, and A.T. Motta, J. Nucl. Mater. 545, 152688. (2021).

44. J. Liu, A.H. Mir, G. He, M. Danaie, J. Hinks, S. Donnelly, H. Nordin, S. Lozano-Perez, and C.R.M. Grovenor, Acta Mater. 199, 429. (2020).

45. J. Zhou, T. Yao, D. Cao, J. Lian, and F. Lu, J. Nucl. Mater 512, 307. (2018).

46. X. Zhang, K. Hattar, Y. Chen, L. Shao, J. Li, C. Sun, K. Yu, N. Li, M.L. Taheri, H. Wang, J. Wang, and M. Nastasi, Prog. Mater. Sci. 96, 217. (2018).

47. W. Liu, Y. Ji, P. Tan, H. Zang, C. He, D. Yun, C. Zhang, and Z. Yang, Materials 9, 105. (2016).

48. B.E. Matthews, M. Sassi, C. Barr, C. Ophus, T.C. Kaspar, W. Jiang, K. Hattar, and S.R. Spurgeon, Nano Lett. 21, 5353. (2021).

49. N. Li, K. Hattar and A. Misra, J. Nucl. Mater 439, 185. (2013).

50. O. El-Atwani, K. Hattar, J.A. Hinks, G. Greaves, S.S Harilal, and A. Hassanein, J. Nucl. Mater. 458, 216. (2015).

51. H. Iwakiri, K. Yasunaga, K. Morishita, and N. Yoshida, $J$. Nucl. Mater 283-287, 1134. (2000).

52. M.A. Tunes, R.W. Harrison, G. Greaves, J.A. Hinks, and S.E. Donnelly, J. Nucl. Mater. 493, 230. (2017).

53. D.C. Bufford, C.S. Snow, and K. Hattar, Fusion Sci. Technol. 71, 268. (2017)

54. R.W. Harrison, S. Ebert, J.A. Hinks, and S.E. Donnelly, J. Eur. Ceram. Soc. 38, 3718. (2018).

55. K. Hojou, S. Furuno, K.N. Kushita, H. Otsu, and K. Izui, J. Nucl. Mater. 191-194, 583. (1992).

56. J.E. Nathaniel, G.A. Vetterick, O. El-Atwani, A. Leff, J.K. Baldwin, P. Baldo, M.A. Kirk, K. Hattar, and M.L. Taheri, J. Nucl. Mater. 543, 152616. (2021).

57. O. El-Atwani, J.E. Nathaniel, A.C. Leff, B.R. Muntifering, J.K. Baldwin, K. Hattar, and M.L. Taheri, J. Nucl. Mater. 484, 236. (2017).

58. M.J. Loeffler, C.A. Dukes, and R.A. Baragiola, J. Geophys. Res: Planets 114, E03003. (2009).

59. O. El-Atwani, J.A. Hinks, G. Greaves, S. Gonderman, T Qiu, M. Efe, and J.P. Allain, Sci. Rep. 4, 4716. (2014).

60. D. Brimbal, B. Décamps, J. Henry, E. Meslin, and A Barbu, Acta Mater. 64, 391. (2014).

61. M.-F. Beaufort, M. Vallet, J. Nicolaï, E. Oliviero, and J.-F. Barbot, J. Appl Phys. 118, 205904. (2015).

62. B. Muntifering, S.J. Blair, C. Gong, A. Dunn, R. Dingreville, J. Qu, and K. Hattar, Mater. Res. Lett. 4, 96. (2016).

63. C.A. Taylor, D.C. Bufford, B.R. Muntifering, D. Senor, M. Steckbeck, J. Davis, B. Doyle, D. Buller, and K.M. Hattar, Materials. 10, 1148. (2017).

64. A. Gentils and C. Cabet, Nucl. Instrum. Methods Phys. Res. Sect. B 447, 107. (2019).

65. R.J. Parrish, D.C. Bufford, D.M. Frazer, C.A. Taylor, J. Gutierrez-Kolar, D.L. Buller, B.L. Boyce, and K. Hattar, Microsc. Today 29, 28. (2021).

66. T. Iwai, Y. Ito, and M. Koshimizu, J. Nucl. Mater. 329-333, 963. (2004)

67. T. Iwai and H. Tsuchida, Nucl. Instrum. Methods Phys. Res. Sect. B 285, 18. (2012).

68. J. Slotte, S. Kilpelainen, N. Segercrantz, K. Mizohata, J. Raisanen, and F. Tuomisto, Phys. Status Solidi A 218, 2000232. (2021).

69. R. Auguste, M.O. Liedke, F.A. Selim, B.P. Uberaga, A. Wagner, and P. Hosemann, J. Mater. 72, 2436. (2020). 
70. M.O. Liedke, W. Anwand, R. Bali, S. Cornelius, M. Butterling, T.T. Trinh, A. Wagner, S. Salamon, D. Waleci, A. Smekhova, H. Wende, and K. Potzger, J. Appl. Phys. 117, 163908. (2015).

71. A. Wagner, M. Butterling, M.O. Liedke, K. Potzger, and R. Krause-Rehberg, AIP Conference Proc. 1970, 040003. (2018).

72. F.A. Selim, Mater. Charact. 174, 110952. (2021).

73. H. Tsuchida, T. Iwai, M. Awano, N. Oshima, R. Suzuki, K. Yasuda, C. Batchuluun, and A. Itoh, J. Nucl. Mater. 442(1, Supplement 1), S856. (2013).

74. M.P. Seah, Vacuum 34, 463. (1984).

75. J.P. Allain, M. Nieto, M.R. Hendricks, P. Plotkin, S.S. Harilal, and A. Hassanein, Rev. Sci. Instrum. 78, 113105. (2007).

76. L. Lukashuk and K. Foettinger, Johnson Matthey Technol. Rev. 62, 316. (2018).

77. F. Bedoya, J.P. Allain, R. Kaita, C.H. Skinner, L. Buzi, and B.E. Koel, Rev. Sci. Instrum. 87, 11D403. (2016).

78. O. El-Atwani, S.A. Norris, K. Ludwig, S. Gonderman, and J.P. Allain, Sci. Rep. 5, 18207. (2015).

79. O. El-Atwani, J.P. Allain, and S. Ortoleva, Nucl. Instrum. Methods Phys. Res. Sect. B 272, 210. (2012).

80. J.K. Tripathi, S.S. Harilal, and A. Hassanein, Mater. Res. Express 1, 035904. (2014).

81. O. Plantevin, R. Gago, L. Vázquez, A. Biermanns, and T.H. Metzger, Appl. Phys. Lett. 91, 113105. (2007).

82. C.N. Taylor, B. Heim, S. Gonderman, J.P. Allain, Z. Yang, R. Kaita, A.L. Roquemore, C.H. Skinner, and R.A. Ellis, Rev. Sci. Instrum. 83, 10D703. (2012).

83. C.J. Beers, C. Jaramillo, N.C. Reid, H. Schamis, J.P. Allain, J.B.O. Caughman, S.J. Meitner, J. Rapp, and S.J. Zinkle, Rev. Sci. Instrum. 92, 045108. (2021).

84. C. Grygiel, H. Lebius, S. Bouffard, A. Quentin, J.M. Ramillon, T. Madi, S. Guillous, T. Been, P. Guinement, D. Lelièvre, and I. Monnet, Rev. Sci. Instrum. 83, 013902. (2012).

85. V.A. Skuratov, K.J. Gun, J. Stano, and D.L. Zagorski, Nucl. Instrum Methods Phys. Res. Sect. B 245, 194. (2006).

86. S. Potdar, R. Gupta, A. Gupta, P.K. Kulriya, and D.K Avasthi, J. Phys. D: Appl. Phys. 48, 015305. (2014).

87. H. Urabe, M. Miyamoto, K. Ono, M. Tokitani, and N. Yoshida, J. Nucl. Mater 386-388, 1038. (2009).

88. M. Hada, S. Ninomiya, T. Seki, T. Aoki, and J. Matsuo, Surf. Interface Anal. 43, 84. (2011).

89. A. Yokoyama, W. Kada, T. Satoh, M. Koka, K. Shimada, Y. Yokoata, K. Miura, and O. Hanaizumi, Nucl. Instrum Methods Phys. Res. Sect. B 371, 340. (2016).

90. E. Langereis, S.B.S. Heil, H.C.M. Knoops, W. Keuning, M.C.M. van de Sanden, and W.M.M. Kessels, J. Phys. D Appl. Phys. 42, 073001. (2009).

91. C.-S. Wong, J.A. Whaley, T. Wada, S. Harayama, Y. Oya, and R.D. Kolasinski, Nucl. Mater. Energy 22, 100730. (2020).

92. K. Ono, M. Miyamoto, T. Nakano, H. Kurata, and Y. Hiraoka, Phys. Scr. T138, 014065. (2009).

93. S. Privitera, A.M. Mio, J. Benke, C. Persch, E. Smecca, A. Alberti, and E. Rimini, MRS Adv. 1, 2701. (2016).

94. L. Beck, Y. Serruys, S. Miro, P. Trocellier, E. Bordas, F. Leprêtre, D. Brimbal, T. Loussouarn, H. Martin, S. Vaubaillon, S. Pellegrino, and D. Bachiller-Perea, J. Mater. Res. 30, 1183. (2015).

95. Y. Zhang, M.L. Crespillo, H. Xue, K. Jin, C.H. Chen, C.L. Fontana, J.T. Graham, and W.J. Weber, Nucl. Instrum Methods Phys. Res. Sect. B 338, 19. (2014).

96. S. Nagata, S. Yamamoto, A. Inouye, B. Tsuchiya, K. Toh, and T. Shikama, J. Nucl. Mater. 367-370, 1009. (2007).

97. S.K. Srivastava, P. Magudapathy, S. Chinnathambi, and P. Gangopadhyay, AIP Conference Proc 2265, 030225. (2020).

98. R. Saavedra, D. Jiménez-Rey, P. Martin, and R. Vila, Nucl. Instrum. Methods Phys. Res. Sect. B 382, 96. (2016).

99. D.V. Sunitha, H. Nagabhushana, F. Singh, N. Dhananjaya, S.C. Sharma, B.M. Nagabhushana, C. Shivakumara, and R.P.S. Chakradhar, Spectroch Acta, Part A 93, 300. (2012).
100. S. Miro, E. Bordas, L. Thomé, J.-M. Costantini, F. Leprêtre, P. Trocellier, Y. Serruys, L. Beck, D. Gosset, R. Verlet, J. Huguet-Garcia, M. Tupin, and M. Belleil, J. Raman Spectrosc. 47, 476. (2016).

101. A. Canizarès, G. Guimbretière, Y.A. Tobon, N. Raimboux, R. Omnée, M. Perdicakis, B. Muzeau, E. Leoni, M.S. Alam, E. Mendes, D. Simon, G. Matzen, C. Corbel, M.F. Barthe, and P. Simon, J. Raman Spectrosc. 43, 1492. (2012).

102. G. Guimbretière, L. Desgranges, A. Canizarès, R. Caraballo, F. Duval, N. Raimboux, R. Omnée, M.R. Ammar, C. Jégou, and P. Simon, Appl. Phys. Lett. 103, 042904. (2013).

103. M. Bricout, C. Onofri, A. Debelle, Y. Pipon, R.C. Belin, F. Garrido, F. Lepretre, and G. Gutierrez, J. Nucl. Mater. 531, 151967. (2020)

104. G. Gutierrez, C. Onofri, S. Miro, M. Bricout, and F. Leprêtre, Nucl. Instrum. Methods Phys. Res. Sect. B 434, 45. (2018).

105. R. Brunetto, G.A. Baratta, and G. Strazzula, J. Appl. Phys. 96,380 . (2004).

106. V. Baranwal, S. Kumar, A.C. Pandey, and D. Kanjilal, J. Alloys Compd. 480, 962. (2009).

107. K.C. Praveen, N. Pushpa, P.S. Naik, J.D. Cressler, H.B. Shiva, S. Verma, A. Tripathi, and A.P. Gnana Prakash, Radiat. Eff. Defects Solids 168, 620. (2013).

108. M. Mikou, R. Carin, P. Bogdanski, and R. Madelon, Nucl. Instrum. Methods Phys. Res. Sect. B 107, 246. (1996).

109. J.A.T. Borges da Costa, M.A.Z. Vasconcellos, S.R. Teixeira, C. Scherer, and M.N. Baibich, Phys. Rev. B 45, 9626. (1992).

110. V.V. Ovchinnikov, V.I. Chernoborodov, and Y.G. Ignatenko, Nucl. Instrum. Methods Phys. Res. Sect. B 103, 313. (1995).

111. M. Toulemonde, J. Dural, G. Nouet, P. Mary, J.F. Hamet, M.F. Beaufort, J.C. Desoyer, C. Blanchard, and J. Auleytner, Phys. Status Solidi A 114, 467. (1989).

112. S. Joneliunas, L. Pranevichius, and R. Valatka, Nucl. Instrum. Methods 182-183, 761. (1981).

113. J. Zuk, H. Kiefte, and M.J. Clouter, J. Appl. Phys. 73, 4951. (1993)

114. G. Sha, C. Harlow, A. Chernatynskiy, J. Daw, and M. Khafizov, Nucl. Instrum. Methods Phys. Res. Sect. B 472, 46. (2020).

115. C.A. Dennett, R.C. Choens, C.A. Taylor, N.M. Heckman, M.D. Ingraham, D. Robinson, B.L. Boyce, M.P. Short, and K. Hattar, J. Mater. 72, 197. (2020).

116. C.A. Dennett, B.R. Dacus, C.M. Barr, T. Clark, H. Bei, Y. Zhang, M.P. Short, and K. Hattar, Appl. Mater. Today 25, 101187. (2021).

117. E.A. Scott, K. Hattar, C.M. Rost, J.T. Gaskins, M. Fazli, C. Ganski, C. Li, T. Bai, Y. Wang, K. Esfarjani, M. Goorsky, and P.E. Hopkins, Phys. Rev. Mater. 2, 095001. (2018).

118. C.A. Dennett, Z. Hua, A. Khanolkar, T. Yao, P.K. Morgan, T.A. Prusnick, N. Poudel, A. French, K. Gofryk, L. He, L. Shao, M. Khafizov, D.B. Turner, J.M. Mann, and D.H. Hurley, Appl. Phys. Lett. Mater. 8, 111103. (2020).

119. I. Alencar, E. Haussühl, B. Winkler, C. Trautmann, B. Schuster, and D. Severin, Acta Mater. 89, 60. (2015).

120. C.A. Dennett, D.L. Buller, K. Hattar, and M.P. Short, Nucl. Instrum. Methods Phys. Res. Sect. B 440, 126. (2019).

121. F. Hofmann, M.P. Short, and C.A. Dennett, MRS Bull. 44, 392. (2019).

122. M.P. Short, C.A. Dennett, S.E. Ferry, Y. Yang, V.K. Mishra, J.K. Eliason, A. Vega-Flick, A.A. Maznev, and K.A. Nelson, J. Mater. 67, 1840. (2015).

123. A.D. Marwick, G.J. Clark, D.S. Yee, R.B. Laibowitz, G. Coleman, and J.J. Cuomo, Phys. Rev. B 39, 9061. (1989).

124. C. Xu and G.S. Was, J. Nucl. Mater. 441, 681. (2013).

125. S.J. Dillon, D.C. Bufford, G.S. Jawaharram, X. Liu, C. Lear, K. Hattar, and R.S. Averback, J. Nucl. Mater. 490, 59. (2017).

126. J.A. Hudson, R.S. Nelson, and R.J. McElroy, J. Nucl. Mater 65, 279. (1977)

127. A.A. Campbell and G.S. Was, J. Nucl. Mater. 433, 86 (2013). 
128. S.A. Briggs, M. Steckbeck, N.M. Heckman, T.A. Furnish, D.C. Bufford, D. Buller, B.L. Boyce, and K. Hattar, Nucl. Instrum. Meth. Phys. Res. B 509, 39. (2021).

129. G.S. Jawaharram, C.M. Barr, A.M. Monterrosa, K. Hattar, R.S. Averback, and S.J. Dillon, Acta Mater. 182, 68. (2020).

130. D.C. Bufford, C.M. Barr, B. Wang, K. Hattar, and A. Haque, J. Mater. 71, 3350. (2019).

131. A. Arbouet, G.M. Caruso, F. Houdellier, Chapter One-Ultrafast Transmission Electron Microscopy: Historical Development, Instrumentation, and Applications, In: P.W. Hawkes (Ed.), Advances in Imaging and Electron Physics, Elsevier 2018, pp. 1-72.

132. J.C. Idrobo, Nat. Rev. Mater. 6, 100. (2021).

133. M. Kjærvik, P.M. Dietrich, A. Thissen, J. Radnik, A. Nefedov, C. Natzeck, C. Wöll, and W.E.S. Unger, J. Electron. Spectrosc. Relat. Phenom. 247, 147042. (2021).

134. S. Schippers, T. Buhr, A. Borovik Jr., K. Holste, A. PerrySassmannshausen, K. Mertens, S. Reinwardt, M. Martins, S. Klumpp, K. Schubert, S. Bari, R. Beerwerth, S. Fritzsche, S. Ricz, J. Hellhund, and A. Müller, X-Ray Spectrom. 49, 11. (2020).

135. J. Ishikawa, H. Tsuji, K. Kameyama, S. Shimada, and Y. Gotoh, Appl. Surf. Sci. 100-101, 370. (1996).

136. D.N. Jamieson, S. Prawer, I. Andrienko, D.A. Brett, and V. Miller, Nucl. Instrum. Methods Phys. Res. Sect. B 175-177, 744. (2001).
137. J.A. Hudson, R.S. Nelson, and B. Ralph, Philos. Mag.: J. Theor. Exper. Appl. Phys. 8, 839. (1968).

138. K.L. Wilson, M.I. Baskes, and D.N. Seidman, Acta Metall. 28, 89. (1980)

139. K. Kantre, M.V. Moro, D. Moldarev, D. Johansson, D. Wessman, M. Wolff, and D. Primetzhofer, Nucl. Instrum. Methods Phys. Res. Sect. B 463, 96. (2020).

140. S.K. J. Shin, University of Illinois, Urbana, IL, Unpubished Research, (2021).

141. P. Liu, K. Yi, I. Jeon, and H. Sohn, NDT and E International 122, 102491. (2021).

142. J.C.S. Wu and Y.-T. Cheng, J. Catal. 237, 393. (2006).

143. W. Xu, D. Raftery, and J.S. Francisco, J. Phys. Chem. B 107, 4537. (2003).

144. R.C. Connick, Massachusetts Institute of Technology (MA, Unpublished Research, Cambridge, 2021).

145. H.K. Yoo, L. Moreschini, A. Bostwick, A.L. Walter, T.W. Noh, E. Rotenberg, Y.J. Chang, Curr. Appl. Phys., (2021).

146. P. Wang and G.S. Was, J. Mater. Res. 30, 1335. (2015).

Publisher's Note Springer Nature remains neutral with regard to jurisdictional claims in published maps and institutional affiliations. 